\title{
Fluid Dynamics of El Niño Variability
}

\author{
Henk A. Dijkstra \\ Institute for Marine and Atmospheric Research, Utrecht University, Utrecht 35B4 CC, \\ The Netherlands; e-mail: dijkstra@phys.uu.nl
}

\section{Gerrit Burgers}

Royal Netherlands Institute for Meteorology, De Bilt 3730 AE, The Netherlands;

e-mail: burgers@knmi.nl

\begin{abstract}
Key Words interannual climate change, equatorial Tropical Pacific, Southern Oscillation, ENSO
\end{abstract}

- Abstract The El Niño variability in the equatorial Tropical Pacific is characterized by sea-surface temperature anomalies and associated changes in the atmospheric circulation. Through an enormous monitoring effort over the last decades, the relevant time scales and spatial patterns are fairly well documented. In the meantime, a hierarchy of models has been developed to understand the physics of this phenomenon and to make predictions of future variability. In this review, the robust and relevant details of the observations, the fluid mechanical "building blocks," the theory of the deterministic part of the variability, and the impact of small-scale ("noise") and remote ("external") processes are evaluated.

\section{INTRODUCTION}

Approximately once every 4 years, the sea-surface temperature in the equatorial eastern Pacific is a few degrees higher than normal (Philander 1990, Glantz 2000). Near the South American coast, this ocean warming is usually at its maximum around Christmas. Peruvian fishermen have called it El Niño, the Spanish phrase for the "Christ Child."

The story of the unmasking of El Niño begins around 1900 in India, where Sir Gilbert Walker studied the variability of the monsoon rainfall. By correlating surface pressures over the Pacific with those in India, Walker discovered a pattern that he called the Southern Oscillation (Walker 1924), The mean surface winds over the equatorial Pacific, the trade winds, blow from east to west and are related to an area of average high pressure in the eastern part of the Pacific and a low pressure area over Indonesia. The Southern Oscillation consists of an irregular strengthening and weakening of the trade winds, related to changes in surface pressure.

In the 1950s, routine measurements of the temperature of the Pacific Ocean were started. The mean temperature in the eastern Pacific is approximately $23^{\circ} \mathrm{C}$, 
with seasonal excursions of approximately $3^{\circ} \mathrm{C}$. During the 1957-1958 El Niño, an extra warming of up to $3^{\circ} \mathrm{C}$ was observed. About a decade later, Jacob Bjerknes found that, simultaneously with this El Niño, the trade winds were much weaker than normal, and he discovered that both El Niño and the Southern Oscillation are part of the same phenomenon (Bjerknes 1969). In this review, the Southern Oscillation is included when we mention El Niño, although the phenomenon is often referred to as (the less fascinating) ENSO (El Niño/Southern Oscillation).

After the strong 1982-1983 El Niño, it was realized that such an event has an enormous impact on the weather over the globe. International monitoring programs were started in the Pacific around 1985 and have led to the permanently maintained TAO/TRITON array. This array consists of some 70 buoys aligned on a grid over the equatorial Pacific basin with a spacing of $2^{\circ}$ in latitude and approximately $15^{\circ}$ in longitude. Simultaneously, a diverse modeling effort has provided a hierarchy of models that are used for understanding, simulation, and prediction. In each of these areas, an enormous amount of literature is available, much of which can be found through a series of reviews in a special issue of the Journal of Geophysical Research (Volume 103, Issue C7, 1998).

We have written this review with a reader in mind who is educated in fluid mechanics, but not necessarily in meteorology and/or oceanography. The aim is to give the reader a framework to understand the fluid dynamics involved in El Niño variability. In Section 2, the problem of characterizing El Niño from available observations is discussed, with focus on the spatio/temporal patterns involved. In Section 3, the fluid-dynamical "building blocks" that are needed to explain the physics of the variability at the dominant spatial (Pacific basin) and temporal (interannual) scales are presented. These building blocks are essentially present in so-called "intermediate complexity models," and concepts of hydrodynamic stability theory are used to explain the behavior of these models (Section 4). In Section 5, the effects of smaller-scale physical processes, usually treated as "noise," and of "external" processes, controlled by factors outside the Pacific basin, are discussed. In the last section, the use of the fundamental knowledge of El Niño in the prediction of future El Niño events is indicated.

\section{OBSERVATIONAL CHARACTERIZATION}

Prior to 1960, the main sources of information on the equatorial Pacific are sealevel pressure data, sea-surface temperature data, as well as precipitation data from surface stations. During the last 10 years, the buoys of the TAO/TRITON array and satellite-borne instruments have observed El Niño in unprecedented detail (McPhaden et al. 1998).

Sea-surface temperature fields have been reconstructed from surface ship reports that are available since 1850 (Kaplan et al. 1998). The uncertainty in the beginning of the instrumental record is at least $0.5^{\circ} \mathrm{C}$. Since the $1980 \mathrm{~s}$, satellite observations make a higher spatial and temporal resolution possible (Reynolds 
\& Smith 1994). However, differences between various products for monthly mean sea-surface temperature indices, based on the same observations, are still approximately $0.2^{\circ} \mathrm{C}$. Outgoing long-wave radiation, which is greatly reduced in regions with deep convection, is also measured by satellites. The analysis of Xie \& Arkin (1997) presents a precipitation product that combines surface, satellite measurements, and model information.

Surface-wind estimates and sea-level measurements have been available from ship reports and island stations since the nineteenth century. Sea-level pressure data from one or a few surface stations can give important information, and this has allowed for the reconstruction of Southern Oscillation indices back to the midnineteenth century (Können et al. 1998). The TAO/TRITON array now provides high-quality surface-wind measurements with high temporal resolution. Simultaneously, satellite scatterometers provide a high spatial resolution. Meteorological models make comprehensive reanalyses of observations. There are still substantial differences between the available wind products. Well-known products based on surface reports are the Florida State University pseudo-stresses, which date back to 1961 (Stricherz et al. 1997).

Ocean subsurface measurements by research vessels are relatively scarce in the equatorial Pacific. The TAO/TRITON buoys measure temperature at various depths down to $500 \mathrm{~m}$, and at some locations subsurface currents are determined as well. Some subsurface measurements of salinity also exist. Sea-level height observations by tide gauges are available at a number of locations, some of them dating back to the 1950s (Wyrtki 1981). Sea level is also measured by satelliteborne altimeters, such as on the TOPEX/POSEIDON satellite. For monthly means with a $2^{\circ}$ resolution, the accuracy of the radar altimeters is within a few centimeters (Cheney et al. 1994).

Nowadays, many data centers have made their observational data sets available on the World Wide Web. The Royal Netherlands Institute for Meteorology maintains a website (http://www.climexp.knmi.nl) where many datasets relevant to El Niño can be obtained, and relationships between data can be investigated.

\subsection{The Climatology}

The first important characteristic of the equatorial Pacific climate system is its climatology, that is, its annual mean state and seasonal cycle (Figure 1). The annual mean sea-surface temperature is characterized by the contrast between the western Pacific "warm pool" and the relatively "cold tongue" in the eastern Pacific. The "warm pool" is also a "fresh pool" because its surface salinity is considerably lower than that around the date line. Although the sun passes over the equator twice a year, the seasonal cycle at the equator is dominated by an annual component. In April (Figure 1b), the east-west contrast in sea-surface temperature along the equator is minimal and in October it is maximal (Figure 1d).

The zonally averaged meridional atmospheric circulation in the Tropics is called the Hadley circulation. At the surface, north-east and south-east trade winds from 
the subtropics meet at the convergence zones in the equatorial regions where air rises. The air returns in the upper troposphere to the subtropics and descends, completing the Hadley circulation. The trade winds are stronger in the winter and spring hemispheres (Figure 1). Along the equator, the trade winds are directed westward toward the convective area over the warm pool where air rises, whereas close to the tropopause, there is eastward flow. In the arid eastern part of the basin there is little or no convection as air descends. The resulting zonal cell over the equatorial Pacific is called the Walker circulation. Both the Hadley and the Walker circulation contribute to the mean atmospheric circulation in the equatorial Pacific.

Owing to the direction of the trade winds, water piles up in the western Pacific where sea level is approximately $50 \mathrm{~cm}$ higher than in the eastern Pacific. Below the surface, there is a rather sharp vertical temperature gradient, called the thermocline, that separates the surface waters from the much colder and more dense water of the bulk of the ocean. It slopes from a depth of approximately $200 \mathrm{~m}$ in the western warm pool toward a depth of appoximately $50 \mathrm{~m}$ in the eastern cold tongue (Figure $2 a$ ). Below the thermocline, the pressure gradient from the variation of the thickness of the lower-density layer above compensates the gradient from the slope of the sea level. The thermocline is sometimes identified with the $20^{\circ} \mathrm{C}$ isotherm. A main feature in the ocean current system of the equatorial Pacific is a generally westward surface flow with velocities as high as $1.4 \mathrm{~ms}^{-1}$ along the equator above an eastward equatorial undercurrent in the thermocline (Philander 1990).

\subsection{The El Niño Pattern}

What makes El Niño unique among other interesting phenomena of natural climate variability is that it has both a well-defined pattern in space and a relatively well-defined timescale. Essentially, El Niño variability amounts to interannual fluctuations in the zonal asymmetry that is so characteristic of the climatology of the Pacific. No sophisticated statistical tools are needed to isolate the El Niño pattern in sea-surface temperature variability. For example, consider the sea-surface temperature anomaly for December 1997 (Figure $2 b$ ), obtained by subtracting the average December temperatures of a long reference period from the December 1997 temperatures. The pattern is characterized by higher than usual temperatures east of the dateline in the equatorial Pacific.

A common index of this sea-surface temperature anomaly pattern is the NINO3 index, defined as the sea-surface temperature anomaly averaged over the region $5^{\circ} \mathrm{S}-5^{\circ} \mathrm{N}, 150^{\circ} \mathrm{W}-90^{\circ} \mathrm{W}$. Its twentieth-century timeseries is shown in Figure $3 a$. Periods with a high index are known as El Niños, and periods with a low index as La Niñas. There is no clear-cut distinction between El Niños, La Niñas, and normal periods; rather, the system exhibits continuous fluctuations of varying strengths and durations. Especially in the eastern Pacific, sea-surface temperature anomalies are positively skewed: El Niños have larger amplitudes than La Niñas (Burgers 


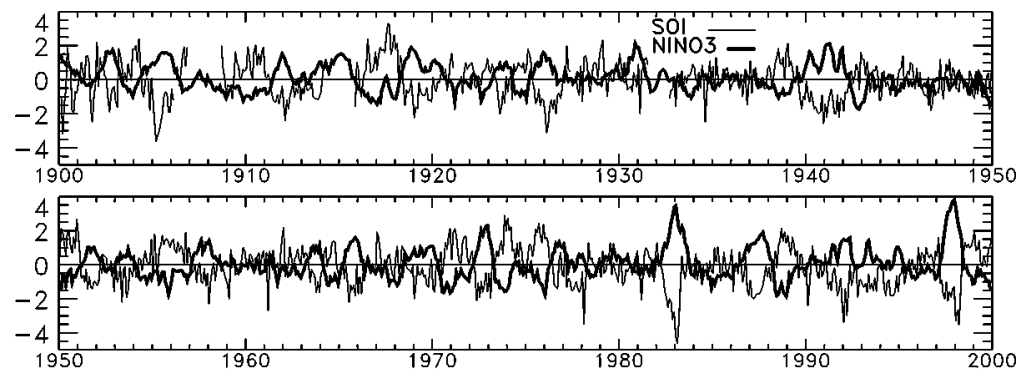

(a)

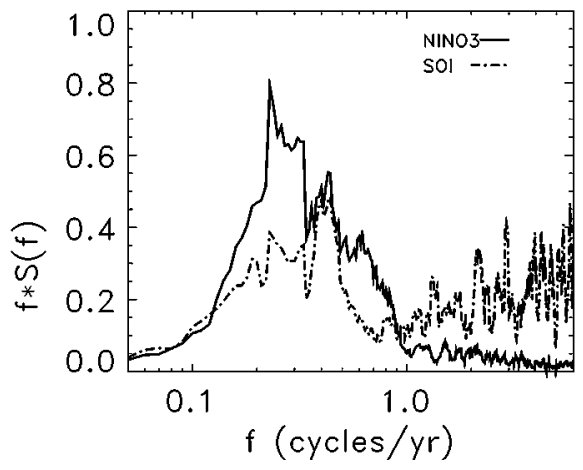

(b)

Figure 3 (a) Monthly mean SOI and NINO3 index over the period 1900-1999. (b) Spectra of monthly mean SOI and NINO3. Shown are normalized periodograms smoothed over 11 bins, that is, over 0.11 cycles per year. Note that the X-axis is logarithmic, and $f * S(f)$ rather than $S(f)$ is shown, so that equal areas make equal contributions to the variance. NINO3 index from NCEP and Kaplan et al. (1998). SOI from NCEP and East Anglia Climate Research Unit (Können et al. 1998).

\& Stephenson 1999). The sea-level pressure anomaly pattern of El Niño can be obtained through correlation with the NINO3 index. The pattern is more global than that of sea-surface temperature. An index that captures the amplitude of this sea-level pressure pattern is the Southern Oscillation index (SOI), which is the normalized difference of the pressure anomalies between Tahiti $\left(18^{\circ} \mathrm{S}, 150^{\circ} \mathrm{W}\right)$ and Darwin $\left(12^{\circ} \mathrm{S}, 131^{\circ} \mathrm{E}\right)$.

Generally, periods with a high NINO3 index have a low SOI and vice versa (Figure $3 a$ ). Over the past 50 years, the correlation between 12-month means of the monthly NINO3 index and the SOI has been close to -0.9 . The spectrum of both the NINO3 index and the SOI is dominated by interannual frequencies (Figure $3 b$ ), but the SOI contains more high-frequency variability and has a white spectral tail, whereas the NINO3 index has a red tail. El Niño is to some extent "phase locked" to the seasonal cycle, as most El Niños and La Niñas peak around December. The 
root mean square (rms) of the NINO3 index is almost twice as large in December as in April.

The wind-stress response associated with a NINO3 anomaly is closely related to the sea-level pressure anomaly pattern. The wind response is concentrated around the equator in an area around the dateline west of the NINO3 area, as shown in Figure $4 a$. This also can be seen in Figure $4 b$, which shows time-longitude diagrams of equatorial zonal wind, sea-surface temperature, and thermocline depth anomalies. The westward response of the wind means that the eastward tradewinds are weakened or reversed during El Niños. Sea-level height and thermocline depth anomalies roughly vary in phase with El Niño in the eastern Pacific and in antiphase in the western Pacific (Figure 4b). On closer inspection, thermocline depth anomalies in the western Pacific seem to precede thermocline depth anomalies and sea-surface temperature anomalies in the eastern Pacific.

\section{FLUID-DYNAMICAL "BUILDING BLOCKS"}

The description of the climatology and variability patterns suggests that the relevant spatial scale is the whole Pacific basin, and the interannual variations in sea-surface temperature, surface winds, and thermocline characterize El Niño.

\subsection{Basic Oceanic and Atmospheric Processes}

The upper ocean is generally well mixed up to a depth of $50 \mathrm{~m}$ (Figure $5 \mathrm{a}$ ). The temperature in this mixed layer changes owing to air-sea interaction, exchange processes with deeper layers, and advection. With the approximation that the temperature is vertically homogeneous over the layer, one can integrate the advection-diffusion equation for the temperature $T$ over the layer, which results in

$$
\frac{\partial T}{\partial t}+u \frac{\partial T}{\partial x}+v \frac{\partial T}{\partial y}=F_{T}^{H}(T)+\frac{Q_{o a}-Q_{b}}{\rho C_{p} H_{m}},
$$

where $C_{p}$ is the heat capacity of water, $H_{m}$ the mean depth of the mixed layer, $\rho$ its mean density, and $(u, v)$ are the horizontal mixed layer velocities. The quantity $F_{T}^{H}$ represents the horizontal mixing of heat trough turbulent exchange processes. The net ocean-atmosphere heat flux $Q_{o a}$ can be parameterized as being proportional to the temperature difference between the upper ocean and lower atmosphere. At the lower mixed layer boundary, an approximation of the heat flux $Q_{b}$ is

$$
\frac{Q_{b}}{\rho C_{p} H_{m}}=w \frac{T-T_{s}}{H_{u}} .
$$

Here, $w$ is a typical vertical velocity at the bottom of the mixed layer, and $H_{u}$ is a vertical length scale such that the temperature gradient between the mixed layer and the subsurface temperature $T_{s}$ is well approximated. 
The upper ocean circulation can be idealized as a two-layer flow with an active upper layer with density $\rho$ that is separated through a sharp density gradient from a bottom layer with density $\rho+\Delta \rho$ in which the horizontal velocities are small (Figure $5 a$ ). The flow in the upper layer is forced by a wind stress $\tau=\tau_{0}\left(\tau^{x}, \tau^{y}\right)$. The reduced-gravity shallow-water ocean model is obtained by integrating the full Navier-Stokes equations on the equatorial $\beta$-plane over the upper layer, the latter having a total thickness $h$. The resulting equations become

$$
\begin{aligned}
\frac{\partial u}{\partial t}+u \frac{\partial u}{\partial x}+v \frac{\partial u}{\partial y}-\beta_{0} y v & =-g^{\prime} \frac{\partial h}{\partial x}+\frac{\tau_{0} \tau^{x}}{h \rho}+F_{M}^{H}(u), \\
\frac{\partial v}{\partial t}+u \frac{\partial v}{\partial x}+v \frac{\partial v}{\partial y}+\beta_{0} y u & =-g^{\prime} \frac{\partial h}{\partial y}+\frac{\tau_{0} \tau^{y}}{h \rho}+F_{M}^{H}(v), \\
\frac{\partial h}{\partial t}+\frac{\partial(u h)}{\partial x}+\frac{\partial(v h)}{\partial y} & =0,
\end{aligned}
$$

where $g^{\prime}=g \Delta \rho / \rho$ is the reduced gravity, $\beta_{0}$ is the gradient of the Coriolis parameter at the equator, and the term $F_{M}^{H}$ represents horizontal exchange of momentum through turbulent processes.

When the unforced $(\tau=0)$ and nondissipative $\left(F_{M}^{H}=F_{M}^{H}=0\right)$ equations are linearized around a motionless mean state $(u=v=0)$ with a constant layer thickness $H$, different types of free wave solutions exist in a zonally unbounded domain (Philander 1990). Two types of low-frequency long waves are relevant for El Niño variability:

1. Equatorial Kelvin waves. The meridional structure of the thermocline structure is maximal at the equator and decays exponentially in meridional direction with decay scale $\lambda_{o}=\sqrt{c_{o} / \beta_{0}}$ (about $300 \mathrm{~km}$ ). The zonal velocity has the same spatial structure as the thermocline, and the meridional velocity is zero. The group velocity of these nondispersive waves is given by $c_{o}=\sqrt{g^{\prime} H}$, which is approximately $2 \mathrm{~m} \mathrm{~s}^{-1}$. It takes approximately 3 months to cross the Pacific basin of width $L=15,000 \mathrm{~km}$.

2. Long equatorial Rossby waves. The meridional thermocline structures of these waves have off-equatorial maxima, and for each of these waves, the meridional velocity is much smaller than the zonal velocity because it scales with $\lambda_{o} c_{o} / L \ll 1$. The group velocity of these nondispersive Rossby waves is $c_{j}=-c_{o} /(2 j+1)$, such that a Rossby wave with $j=1$ travels westward with a velocity that is one third that of the Kelvin wave.

When a Kelvin wave meets the east coast, the dominant contribution of the reflected signal are long Rossby waves. Similarly, when a Rossby wave meets the west coast, it is reflected dominantly as a Kelvin wave.

The small-amplitude response of the flow in a zonally bounded ocean basin to a certain wind field can be described as a directly forced response and a sum of free waves to satisfy the boundary conditions (Moore 1986, Cane \& Sarachik 
1977). A Green's function for the long-wave response can be constructed under the boundary conditions of no zonal mass flux at the western boundary and no normal velocity at the eastern boundary; analytical expressions can be derived in special cases (Cane \& Moore 1981, Neelin \& Jin 1993). In response to a time-periodic wind stress, the ocean not only reacts to the instantaneous wind pattern, but also adjusts to previous winds through propagation of waves. Along the equator, the latter adjustment is mainly accomplished by relatively fast eastward Kelvin waves, and in off-equatorial regions, this is accomplished by slower Rossby waves that travel westward. The off-equatorial thermocline pattern consists partly of free Rossby waves that are adjusting to the wind and partly of a forced response that is in quasi-steady balance with the instantaneous wind stress. The departure of this quasi-steady balance is crucial to the further evolution of the thermocline and provides the ocean with a memory (Neelin et al. 1998). For the wind patterns over the Tropical Pacific, this "ocean memory" is largest near the western boundary.

Apart from an effect on the thermocline, the winds also cause divergences and convergences of mass in the mixed layer, owing to the frictional (Ekman) boundary layer in which the momentum input is transferred. North of the equator, the trade winds cause an Ekman transport to the right of the wind away from the equator. Similarly, south of the equator, the Ekman mass transport is away from the equator. Vertical velocities $w_{E}$ originate in the Ekman layer, by continuity, and lead to upwelling. If the frictional processes in the Ekman layer are idealized to be linear, with damping coefficient $a_{s}$, then a balance of the frictional processes, the Coriolis effect and wind stress lead to

$$
\begin{aligned}
& a_{s} u_{E}-\beta_{0} y v_{E}=\frac{\tau_{0} \tau^{x}}{\rho H_{m}}, \\
& a_{s} v_{E}+\beta_{0} y u_{E}=\frac{\tau_{0} \tau^{y}}{\rho H_{m}},
\end{aligned}
$$

where the subscript $E$ refers to the Ekman-layer velocities. With a wind-stress amplitude $\tau_{0}=0.05 P a$ and $a_{s}=5.0 \times 10^{-6} \mathrm{~s}^{-1}$, a typical value of $w_{E}$ is a few meters per day.

The circulation of the tropical atmosphere is sensitive to sea-surface temperature anomalies. Basically, if the underlying sea surface is warmer, the air above it is heated and rises. A conceptual model to determine the low-level wind response due to heating anomalies in the tropics was analyzed by Gill (1980). The equations are

$$
\begin{aligned}
\frac{\partial U}{\partial t}-\beta_{0} y V & =\frac{\partial \Theta}{\partial x}+F_{A}^{H}(U), \\
\frac{\partial V}{\partial t}+\beta_{0} y U & =\frac{\partial \Theta}{\partial y}+F_{A}^{H}(V), \\
\frac{\partial \Theta}{\partial t}-c_{a}^{2}\left(\frac{\partial U}{\partial x}+\frac{\partial V}{\partial y}\right) & =Q_{H}+F_{A}^{H}(\Theta),
\end{aligned}
$$


where $(U, V)$ are the low-level winds, $\Theta$ the geopotential height, and $c_{a}$ is the phase speed of the Kelvin wave in the atmosphere. A typical value of the latter is $c_{a}=30 \mathrm{~m} / \mathrm{s}$, such that the ratio of the meridional decay scales of atmosphere $\left(\lambda_{a}=\sqrt{c_{a} / \beta_{0}}\right)$ and ocean is about 4 . The flow is forced by diabatic heating $\left(Q_{H}\right)$, and in many cases, the horizontal exchange terms $F_{A}^{H}$ are idealized as linear.

It is problematic to specify the relationship between the diabatic heating structure and the sea-surface temperature anomalies. The simplest connection arises when one assumes that the diabatic heating is dominated by heat that is released during precipitation that occurs mostly over the warmest surface water. In this way, the heating is related to the low-level moisture convergence, and when the vertical structure of the heating is fixed, a direct coupling with sea-surface temperature anomalies $\mathrm{T}$ (with respect to some mean state) and latent heating anomalies $Q_{H}$ results (Zebiak 1982), i.e.,

$$
Q_{H}=\alpha_{T} T
$$

with a (constant) coefficient $\alpha_{T}$. Using this in Equation 5, a low-level wind response is found with westerly (easterly) winds to the west (east) of positive (negative) sea-surface temperature anomalies. When observations are analyzed, the relation (Equation 6) is far from perfect, and it is also hard to justify this relation from the governing equations of atmospheric motion. Over the last decade, more detailed theory has been developed to describe the physics of atmospheric convection and its effect on the large-scale flow. This has led to new tropical atmospheric models, such as quasi-equilibrium models (Neelin \& Zeng 2000).

\subsection{Coupled Processes}

The nature of the coupling between ocean and atmosphere can now be explained (Figure $5 a$ ). A sea-surface temperature anomaly will give, through local heating, a low-level wind anomaly. The resulting wind-stress anomaly on the oceanatmosphere surface will change the thermocline slope through horizontal pressure differences in the upper ocean and will affect the upper ocean currents $(u, v)$ and upwelling in the mixed layer. The change in velocity field and thermocline field will affect the sea-surface temperature, according to Equation 1.

The strength of the coupling is determined by the combined effects of how much low-level zonal-wind anomaly is generated by sea-surface temperature anomalies and how much of the momentum of this wind is transferred as stress to the upper ocean layer. In many models, a simple (linearized) relation between anomalies of wind stress $\tau$ and wind velocity anomalies is assumed, with proportionality constant $\gamma$. The strength of the coupling is then measured, using Equation 6, by the parameter $\mu$, which is a (dimensionless) product of $\alpha_{T}$ and $\gamma$, i.e.,

$$
\mu=\frac{\gamma \alpha_{T} \Delta T L^{2}}{c_{o}^{2} c_{a}^{2}},
$$


where the quantity $\Delta T$ is a typical horizontal temperature difference over the basin. The coupling strength $\mu$ is the main parameter controlling the stability of the coupled system. Three feedbacks, i.e., thermocline, upwelling, and zonal advection feedback, have been identified in this coupled ocean-atmosphere system (Neelin 1991).

The thermocline feedback is best explained by looking at a sloping thermocline in a constant upwelling $(\bar{w}>0)$ ocean, as sketched in Figure $5 b$. The sloping thermocline and the upwelling are caused by the background easterly winds. Now assume that a positive sea-surface temperature anomaly $\tilde{T}$ is present at some location, for example, in the eastern part of the basin. This leads to a perturbation in the low-level zonal wind, which is westerly with a maximum located west of the maximum of $\tilde{T}$. Since the background winds are locally weakened, the slope of the thermocline decreases (red arrows in Figure $5 b$ ). The colder water will be closer to the surface in the west, but it will be farther down in the east. Hence, the subsurface temperature effectively increases at the level of upwelling, giving a positive heat-flux perturbation at the bottom of the mixed layer. According to Equations $1-2$, i.e., $\partial \tilde{T} / \partial t \approx-\bar{w}\left(\tilde{T}-\tilde{T}_{s}\right) / H_{u}$, when $\tilde{T}_{s}-\tilde{T}>0$, the anomaly $\tilde{T}$ is amplified because $\bar{w}$ is positive. The thermocline feedback is present in a transient state as well as in an adjusted state.

To understand the upwelling feedback, consider again a positive sea-surface temperature anomaly $\tilde{T}$ in the eastern part of the basin and associated changes in the wind. However, now changes in the upwelling $\tilde{w}$ occur as a result of Ekman-layer dynamics. Weaker easterly winds imply less upwelling, and hence, less colder water enters the mixed layer (blue arrows in Figure $5 b$ ). If $\tilde{w}<0$ and the background vertical-temperature gradient is stably stratified $\left(\bar{T}>\bar{T}_{S}\right)$, then the sea-surface temperature perturbation is amplified. The latter also follows from Equations 1-2, i.e., $\partial \tilde{T} / \partial t \approx-\tilde{w}\left(\bar{T}-\bar{T}_{s}\right) / H_{u}$.

For the zonal advection feedback, imagine a region with a strong mean seasurface temperature gradient, say, $\partial \bar{T} / \partial x<0$. Such a region occurs, for example, at the east side of the warm pool. Suppose a positive anomaly in sea-surface temperature $\tilde{T}$ occurs leading again to westerly wind anomalies. Consequently, the zonal-surface ocean current $(\tilde{u}>0)$ is intensified (green arrows in Figure $5 b$ ) leading to amplification of the positive-temperature perturbation, according to Equation 1, i.e., $\partial \tilde{T} / \partial t \approx-\tilde{u} \partial \bar{T} / \partial x$. Part of the mixed-layer zonal velocity will be due to wave dynamics and part due to Ekman dynamics.

\subsection{Intermediate Complexity Models}

When all the building blocks above are integrated into one model, a so-called intermediate complexity model (ICM) results (Zebiak \& Cane 1987). In the ocean component, a nesting of a mixed-layer model and a two-layer dynamical model (as shown in Figure 5a) is used. The depth-averaged horizontal velocity, say, $\mathbf{u}_{M}$, satisfies shallow-water dynamics, whereas the difference velocity, say, $\mathbf{u}_{E}$, satisfies Ekman dynamics. The mixed-layer velocities in Equation 1 are then given by 
$\mathbf{u}=\mathbf{u}_{M}+\mathbf{u}_{E}$, and a closed system of equations is obtained once the subsurface temperature $T_{s}$ is expressed into the thermocline deviation from its equilibrium value.

Intermediate complexity models differ in the representation of $(a)$ the atmospheric response to sea-surface temperature anomalies (Kleeman 1991), $(b)$ the representation of the heat fluxes $Q_{o a}$ and $Q_{b}$ in the sea-surface temperature equation (Battisti \& Hirst 1989), and (c) representations of the vertical stratification and boundary layers in both the ocean and atmosphere (Anderson \& McCreary 1985). In Neelin (1991), a simplification of the full sea-surface temperature equation to an equatorial strip is introduced by meridional differencing. This reduces considerably the complexity of the model, and analytical progress can be made on the behavior of the solutions of the coupled model.

Most of these models have been run in anomaly mode, which means that the model is only used to compute the anomalies with respect to a prescribed climatology, the latter being an annual mean state or a seasonal cycle. The corresponding behavior, relevant for the discussion below, in these models can be summarized as follows. There exists a broad parameter range where oscillatory behavior is found on interannual timescales, with recurrent warm and cold events each lasting approximately 14-18 months. The eastern-Pacific sea-surface temperature anomalies have an amplitude of approximately $2-3^{\circ} \mathrm{C}$. When the coupling strength $\mu$ decreases, the interannual oscillatory behavior disappears. This suggests that there is some critical threshold associated with instabilities in the coupled system related to the positive feedbacks as described in the previous subsection. The annual cycle contributes to the irregularity of the interannual oscillation. The (northern) summer appears to be most favorable for rapid growth of sea-surface temperature anomalies, and spring seems less favorable.

\section{DETERMINISTIC EL NIÑO VARIABILITY}

The results of ICMs indicate that it is very likely that some preferred spatial pattern and timescale of variability is introduced through coupled feedbacks. In this section, the results on how such a preferred pattern may arise as an instability on a particular mean state are reviewed. Details on the different stability and bifurcation analyses can be found in Dijkstra (2000).

\subsection{Mean States}

The different results can be ordered according to the mean state chosen within a particular intermediate complexity model, which can be prescribed, constructed, or fully coupled. A prescribed state is not a solution of the governing equations of the coupled model. For example, a flat thermocline can be chosen, with a spatially constant zonal-temperature gradient and no flow in both ocean and atmosphere (Hirst 1986). Otherwise, an annual mean state or seasonal cycle from observations can be prescribed (Zebiak \& Crane 1987). 
A constructed state is a solution of the ocean model and sea-surface temperature equation, but not of the atmosphere model. One way to construct such a mean state in an ICM is by forcing the ocean model by observed winds $\tau_{o b s}$. The resulting steady-state temperature is indicated by $\bar{T}$. In the coupled model, the wind stress $\tau$ fed into the ocean model is $\tau=\tau_{o b s}+\mu \mathcal{A}(T-\bar{T})$, where $\mu$ is the coupling parameter and the operator $\mathcal{A}$ represents the atmosphere model equations. Hence, there is a constructed solution, $T=\bar{T}, \tau=\tau_{\text {obs }}$, that does not depend on coupling. In this way, the coupling strength $\mu$ only influences the stability of the mean state to perturbations (Jin \& Neelin 1993), but not the mean state itself.

A fully coupled state is a solution of the coupled model equations. The construction of these states starts with the recognition that part of the (annual mean) wind stress in the Pacific basin is in fact related to its zonal-temperature gradient (Neelin \& Dijkstra 1995). Only a small part of the wind stress, say $\tau_{\text {ext }}$, is determined externally. The part determined within the basin depends on temperature departures from surface heat-flux equilibrium, i.e., $\tau=\tau_{\text {ext }}+\mu \mathcal{A}\left(T-T_{0}\right)$, where $T=T_{0}$ is the temperature of the upper ocean in absence of any oceanic and atmospheric motion. In this way, the mean winds are determined by the coupled model, and the mean state as well as its stability depend on $\mu$. In this case, no multiple equilibria occur, contrary to the situation in which this state is constructed (Neelin \& Dijkstra 1995).

In the latter approach, the external wind stress $\tau_{\text {ext }}$ can be taken to be zonally constant, imagined as being caused by the zonally symmetric atmospheric circulation. At zero coupling strength $(\mu=0)$, the ocean circulation, and consequently the sea-surface temperature, is determined by the external zonal-wind stress $\tau_{e x t}^{x}$. Within the model used in Van der Vaart et al. (2000), in response to such an external wind, with amplitude $0.01 \mathrm{~Pa}$, the equatorial sea-surface temperature increases monotonically from approximately $25.5^{\circ} \mathrm{C}$ in the east to approximately $28.5^{\circ} \mathrm{C}$ in the west. The equatorial thermocline is approximately linear, its depth is increasing westward, and it has slight off-equatorial maxima near the western boundary. At small $\mu$, additional easterly wind stress due to coupling occurs because of the zonal-temperature gradient. This leads to larger upwelling and a stronger thermocline slope, strengthening the cold tongue in the eastern part of the basin. The temperature of the cold tongue $T_{C}$ (actually $T_{C}-T_{0}$ ) is shown in Figure $6 a$ as a function of $\mu$. The zonal scale of the cold tongue is set by a delicate balance of the coupled feedbacks (Dijkstra \& Neelin 1995). The thermocline field at $\mu=0.5$ (Figure $6 b$ ) displays the off-equatorial maxima and a deeper (shallower) equatorial thermocline in the west (east).

Fully coupled mean states with seasonal time dependence, having the correct seasonal equatorial temperature distribution are difficult to obtain within the intermediate complexity models. There are strong indications that coupled processes, in particular those in the surface layer, are involved in getting an annual response to a semiannual forcing (Philander et al. 1996). Conceptual studies have identified the equatorial north-south asymmetry as a crucial factor in the seasonal cycle 


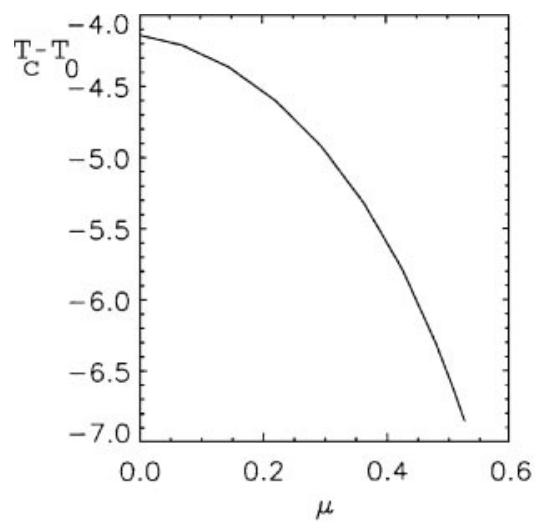

(a)

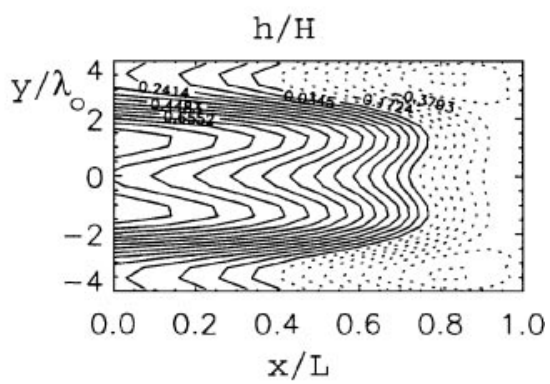

(b)

Figure 6 (a) Eastern Pacific $(x / L=0.8)$ equatorial sea-surface temperature deviation from $T_{0}=30^{\circ} \mathrm{C}$ as a function of the coupling strength $\mu$. (b) Pattern of the thermocline depth anomaly at $\mu=0.5$; maximum amplitude is $82 \mathrm{~m}$, and contours are with respect to this maximum.

(Xie \& Philander 1994), with both evaporation (in combination with the response of the wind) and vertical mixing being able to amplify equatorial asymmetries.

\subsection{Stability of Mean States}

Necessary conditions for instability can be obtained by determining the linearstability boundary through normal-mode analysis. When the mean state is stationary, the linearized equations admit solutions proportional to $e^{\sigma t}$, where $\sigma=\sigma_{r}+i \sigma_{i}$ is the complex-growth rate. If $\mu$ is a control parameter, then the linear-stability boundary $\mu_{c}$ is the first value where $\sigma_{r}=0$ for one particular normal mode. The stability of the annual periodic orbit has to be determined through Floquet analysis.

Early studies included the stability of a spatially constant mean state in a periodic ocean basin. In this case, both uncoupled ocean and atmospheric Rossby and Kelvin waves may destabilize as a result of the coupled feedbacks. The resulting unstable modes are traveling waves, which have an interannual oscillation period for wavelengths of the order of the basin size (Philander et al. 1984, Hirst 1986). Also, a slow westward-propagating mode, a so-called SST-mode, which is not related to wave dynamics in either the atmosphere or the ocean, may become unstable (Neelin 1991).

The linear stability of constructed mean states within a zonally bounded basin has been investigated by Jin \& Neelin (1993). A large region in parameter space involving analytically tractable limits was considered (reviewed in Neelin et al. 1994). In the uncoupled case, two distinct sets of modes occur that are primarily related to the timescales of sea-surface temperature change (the above-mentioned 
SST modes) and to the timescales of ocean adjustment (ocean-dynamics modes). The latter arise from the linearized operator associated with the shallow-water model (Equation 3). A complication arises because the total spectrum of this operator consists of an essentially continuous part (Moore 1968) in addition to the (discrete) classical ocean-basin modes (Cane \& Moore 1981). In numerical models, the continuous spectrum shows up as resolution-dependent "scatter-modes." Depending on the other parameters in the model, the mean state can become unstable to stationary instabilities as well as oscillatory ones. In the parameter regime considered "most realistic," referred to as the standing oscillatory regime, merging of an oscillatory ocean-dynamics mode with a stationary SST mode occurs. This leads to slightly unstable (so-called mixed SST/ocean-dynamics) modes that inherit spatial structure from the stationary SST mode, but for which the interannual oscillation period is set by ocean subsurface dynamics (Neelin et al. 1994).

The linear stability of fully coupled steady states (e.g., see Figure 6) is determined in Van der Vaart et al. (2000). In Figure 7a, the path of six modes-which become leading eigenmodes at high coupling —is plotted as a function of the coupling

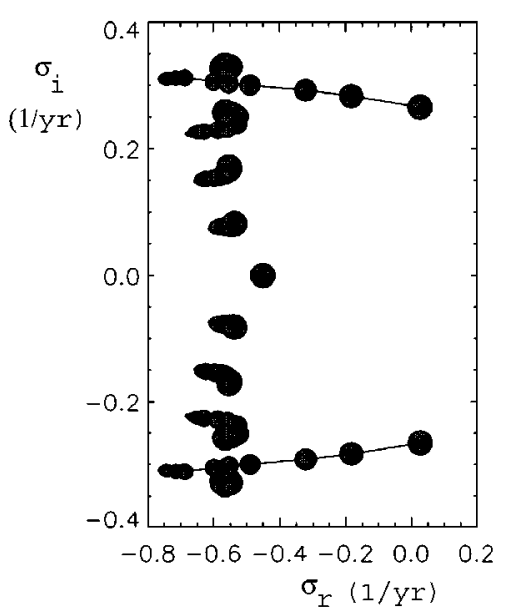

(a)
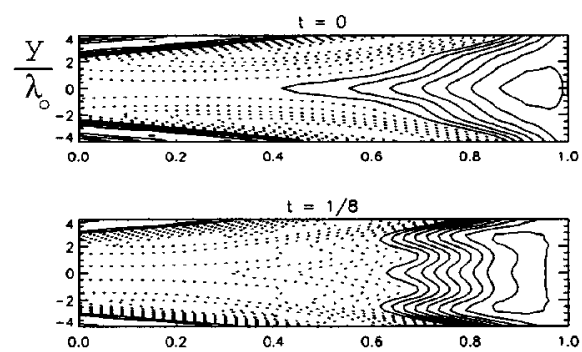

$t=1 / 4$
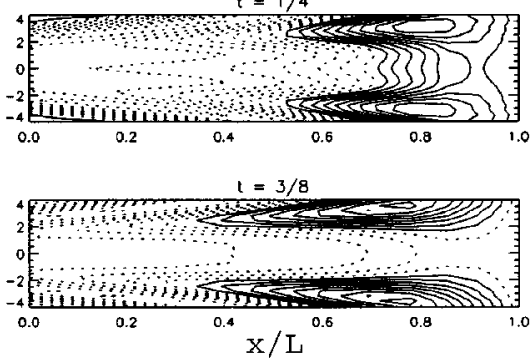

(b)

Figure 7 (a) Plot of the eigenvalues for the six leading eigenmodes in the $(\operatorname{Re}(\sigma), \operatorname{Im}(\sigma))$ plane. Values of the coupling strength $\mu$ are represented by dot size (smallest dot is the uncoupled case $(\mu=0)$ for each mode, largest dot is the fully coupled case at the Hopf bifurcation $\left.\left(\mu_{c}=0.5\right)\right)$. (b) Planforms of the thermocline depth anomaly at several phases of the 3.7-year oscillation of the neutral mode; time $t=1 / 2$ refers to half a period, and amplitudes are arbitary. Drawn (dotted) lines represent positive (negative) anomalies. 
strength $\mu$. A larger dot size indicates a larger value of $\mu$, and both oscillation period and growth rate of the modes are given in (year) ${ }^{-1}$. One oscillatory mode becomes unstable as $\mu$ is increased, and a Hopf bifurcation occurs at $\mu=0.5$. The equatorial sea-surface temperature of the neutral mode displays a nearly standing oscillation for which the spatial pattern is localized in the cold tongue region. The zonal-wind anomalies are in phase with the sea-surface temperature anomalies. In the spatial structure of the thermocline field (plotted in Figure $7 b$ at several phases of the oscillation), the eastward propagation of equatorial anomalies, their reflection at the eastern boundary, and subsequent off-equatorial westward propagation can be distinguished.

Strict Floquet analysis has only been applied to constructed mean states with seasonal time dependence (Jin et al. 1994, 1996). The pattern of the mode that becomes unstable through a Hopf bifurcation on the annual mean state is very similar to that destabilizing the seasonal cycle. This result is confirmed by other studies in which a "poor man's" stability analysis is performed by computing trajectories of the model under changing parameters (Tziperman et al. 1995).

\subsection{Nonlinear Equilibration}

In each of the models above, oscillatory El Niño behavior is found slightly above critical conditions, followed by irregular behavior at stronger coupling. Attempts have been made to derive conceptual models to explain the physics of the oscillation period and the transition to irregularity. Most of these share the ideas that $(a)$ one of the positive feedbacks (as discussed in Section 3) acts to amplify sea-surface temperature anomalies and $(b)$ adjustment processes in the ocean eventually cause a delayed negative feedback. These common elements are grouped together in the delayed-oscillator mechanism or subsurface memory paradigm. The differences between the views are subtle (Jin 1997b) and are related to (a) the role of the boundary wave reflections, $(b)$ the importance of the adjustment processes of seasurface temperature, $(c)$ the dominant feedback that is responsible for amplification of anomalies, and $(d)$ the view of the dynamical adjustment processes in the ocean.

In the classical delayed-oscillator view, the eastern-boundary reflection is unimportant, the thermocline feedback is dominant, and individual Kelvin and Rossby waves control ocean adjustment. A conceptual model (Suarez \& Schopf 1988, Battisti \& Hirst 1989) representing this behavior is a differential delay equation of the form

$$
\frac{d T(t)}{d t}=a T(t)-b T(t-d)-c T^{3}(t) .
$$

When a Kelvin wave, which deepens the thermocline, arrives in the eastern-Pacific local amplification of temperature perturbations occurs through the thermocline feedback, leading to a growth rate $a$ in Equation 8. The wind response excites (offequatorial) Rossby waves, which travel westward, reflect at the western boundary, and return as a Kelvin wave that rises the thermocline and provides a delayed 
negative feedback with strength $b$ in Equation 8. The coefficient $d$ is the time taken for the Rossby wave to travel from the center of the wind response to the western boundary plus the time it takes the reflected Kelvin wave to cross the basin. The nonlinear term is needed for equilibration to finite amplitude. Variants of these models were also considered in Schopf \& Suarez (1990) and in the coupledwave oscillator model (Münnich et al. 1991). They share the view that sea-surface temperature anomalies adapt instantaneously to thermocline anomalies, and hence, ocean adjustment is only through equatorial waves.

In Jin (1997a), the ocean adjustment is viewed as being caused by a collective of Kelvin and Rossby waves, and adjustment of sea-surface temperature through surface-layer processes is important. Consider again a positive sea-surface temperature anomaly in the eastern part of the basin that induces a westerly wind response. Through the thermocline feedback, the sea-surface temperature anomaly is amplified, which brings the oscillation to the extreme warm phase (Figure $8 a$ ). Because of ocean adjustment, a nonzero divergence of the zonally integrated mass transport occurs, and part of the equatorial heat content is moved to off-equatorial regions. This exchange causes the equatorial thermocline to flatten and reduces the easterntemperature anomaly (again the thermocline feedback plays a role), and consequently the wind stress anomaly vanishes (Figure $8 b$ ). After a while, a basin-wide negative equatorial thermocline anomaly is generated, which allows cold water to get into the surface layer by background upwelling. This causes a negative seasurface temperature anomaly leading through amplification to the cold phase of the cycle (Figure $8 c$ ). Through adjustment, the equatorial heat content is recharged
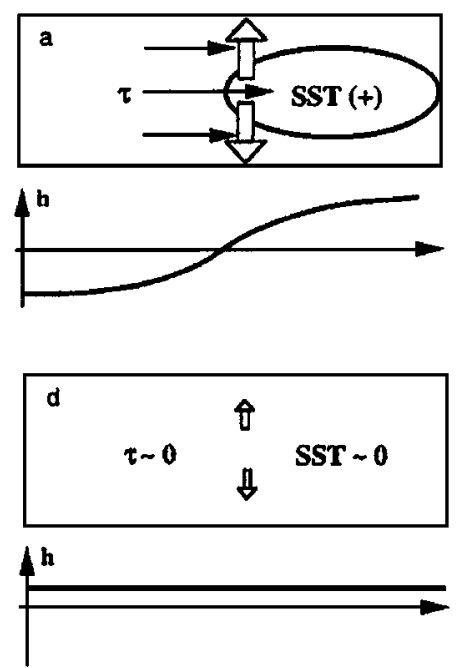
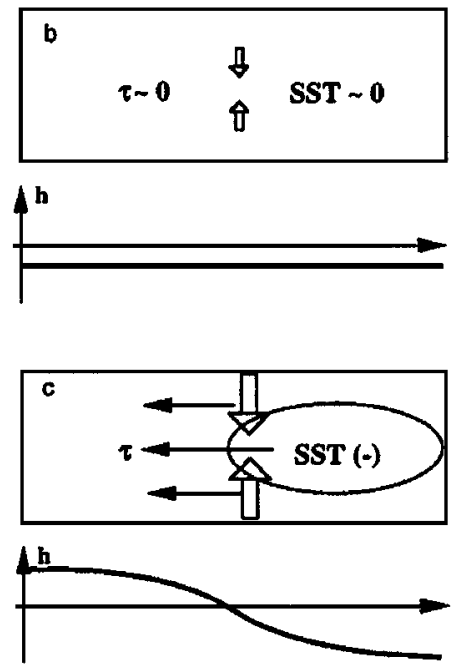

Figure 8 Sketch of the different stages of the recharge oscillator (Jin 1997a). 
and leads to a transition phase with a positive basin-wide equatorial thermocline anomaly (Figure $8 d$ ). This recharge oscillator view can be easily adapted to include effects of zonal advection (Jin \& An 1999) as the zonal advection feedback and the thermocline feedback induce the same tendencies of sea-surface temperature anomalies.

When the mean state is time dependent and has an annual period, the nonlinear equilibration is more complicated. For a constructed annual cycle, the supercritical behavior has been clarified by studying regimes in a two-parameter plane (Jin et al. 1994). One of these parameters is the coupling strength $\mu$, and the other is a dimensionless parameter $\delta_{s}$ that controls the strength of the upwelling feedback. When the coupling strength is increased above criticality, the solution displays regimes of frequency locking to the annual cycle alternated by chaotic regimes. The latter arise through overlapping Arnold tongues, as in the classical quasiperiodicity route to chaos. The mosaic of the different frequency locked and chaotic regimes in the $\left(\mu, \delta_{s}\right)$ plane is referred to as the Devil's Terrace. Although chaotic solutions are nearly everywhere in parameter space over a fractal surface, the locked regime is very broad. For many solutions found, the phase locking to the annual cycle is like that observed, with January being the preferred month of the peak of the warm event. Similar results have been obtained in the coupled wave oscillator model (Tziperman et al. 1994).

The physics of interaction between seasonal cycle and El Niño variability is still not fully understood (Tziperman et al. 1998). Based on the Zebiak-Cane ICM, Tziperman et al. (1997) pointed to the seasonality of the atmosphere as the main cause of frequency locking, with effects of seasonal ocean changes being secondary. Using a more elaborate ICM, which simulates both the coupled seasonal cycle and El Niño, Chang et al. (1994) stressed the relative importance of the amplitude of the seasonal cycle and showed that the El Niño frequency gets entrained (disappears from the signal) if the amplitude of the seasonal cycle becomes too large. Note that the presence of the seasonal cycle is not necessary for the appearance of chaotic behavior. With perpetual July conditions as mean state, the coupled system has a nearly continuous frequency spectrum at large coupling strength (Mantua \& Battisti 1995).

\section{MULTISCALE PHYSICS}

Intermediate complexity models give a clear deterministic framework for explaining El Niño variability. However, these models represent only part of the Pacific ocean-atmosphere system. One may ask (a) which elements of this deterministic framework remain identifiable when placed in the context of a multiscale physical system and $(b)$ whether new elements that enter change the view of El Niño variability. Both observations and model results can provide representations of this multiscale system. Two classes of models can be distinguished: hybrid coupled models (HCMs) and coupled general circulation models (CGCMs). Both types 
of models consist of an ocean general circulation model (OGCM), but the atmospheric components differ substantially. Whereas in CGCMs (Delecluse et al. 1998) the atmosphere is a full physical-dynamical model, in HCMs it is a statistical model (Eckert \& Latif 1997) in which the atmospheric response to variations in sea-surface temperature is captured by relations from data. Recently, two new intercomparison studies of these models have been completed, one in which the focus is on the Pacific only (ENSIP) (M. Latif \& K. Sperber, submitted) and the other on the whole Tropical climate system (STOIC) (M. Davey, M. Huddleston, \& K.R. Sperber, submitted). Although there has been considerable progress in modeling El Niño with CGCMs, none of the models simulates all aspects of interannual variability well. This means that some care must be taken in drawing conclusions from studies with CGCMs.

\subsection{Recognition of Building Blocks}

Can we recognize the "building blocks" mentioned in the previous section in the results of comprehensive models and measurement programs? Examining the observations shown in the time-longitude diagrams of Figure $4 b$, one recognizes that sea-surface temperature anomalies in the eastern and central Pacific are associated with same-sign zonal-wind anomalies further west. Thermocline anomalies have a tendency to propagate from the west to the east, whereas sea-surface temperature variations are dominated by a standing component. Most of these aspects are reasonably captured by intermediate complexity models. However, in contrast to the atmosphere response in many intermediate models, there are no clear systematic zonal-wind anomalies west of the sea-surface temperature anomalies.

The strong relation between sea-surface temperature anomalies and thermocline anomalies in the eastern Pacific (Figure $4 b$ ) is an indication of the action of the thermocline feedback. However, it is hard to make a distinction between the thermocline and the zonal advection feedback (Picaut et al. 1996) because both have the same signature in a Kelvin wave. The central part of the Pacific exhibits the strongest correlations between local sea-surface temperature and wind. This is an indication that the zonal advection feedback and upwelling feedback are important. In this region, a large mean zonal temperature gradient and large wind anomalies are present. It is probable that local-wind effects are important for the sea-surface temperature development in the central Pacific, and wave-dynamic adjustment effects may dominate in the eastern Pacific.

Structures that correspond to the Kelvin and Rossby waves, and reflection of these waves, have been observed by altimetry and TAO/TRITON measurements (Boulanger \& Menkes 1999, McPhaden \& Yu 1999). A complication in establishing properties of these waves, such as wave speeds and reflection coefficients, arises from the interaction of waves with the wind-stress variability, resulting in a huge uncertainty.

In CGCMs, wave reflection is well established, although wave dynamics is much more complicated than in intermediate models because there are several vertical 
modes instead of one and because the background state is not homogeneous and constant. Schneider et al. (1995), who compare a simulation driven by observed winds to one driven by winds with the evolution in reversed time, present an elegant demonstration of the role of wave dynamics. In Oldenborgh et al. (1999), the sensitivity of the NINO3 index to earlier sea-level and wind stress fields is determined. Kelvin and Rossby waves can be seen in sea-level influence fields that travel over the Pacific and reflect at the western boundary in agreement with the delayed-oscillator picture. A study of the energetics of El Niño variability (Goddard \& Philander 2000) with an ocean general-circulation model also suggests a strong role for the delayed-oscillator mechanism. In the half cycle after the El Niño peak, energy is fed into the ocean by the wind in the central and western Pacific, generating perturbation buoyancy power. The gained energy adjusts via equatorial wave dynamics and wave reflection and is released to the atmosphere before the next El Niño peak.

In the far western Pacific, easterly wind anomalies appear from December to April during El Niños. Wang et al. (1999) introduced a mechanism that could cause these anomalies and proposed an alternative to wave reflection for the negative feedback that terminates El Niño.

\subsection{Noise and Its Role in El Niño}

From the perspective of El Niño, processes that evolve independently with smaller time-and space scales can be considered as "noise." Noise has an important influence on the irregularity and predictability of El Niño and probably is also important for sustaining El Niño variability.

In the atmosphere, an important phenomenon is the 30-60 day, or MaddenJulian, oscillation (Madden \& Julian 1994). This oscillation gives rise to westerly wind bursts, events of anomalous westerlies lasting typically a week, which are strongest somewhat west of the region of the El Niño wind response (Weller \& Anderson 1996, Vecchi \& Harrison 2000). They are stronger in boreal winter and spring, and are enhanced by local air-sea interaction. The Madden-Julian oscillation has substantial interannual variability, and although El Niño events do not seem to affect westerly wind bursts, their location may shift slightly (Slingo et al. 1999). The atmospheric variability causes not only wind-stress anomalies, but also heating anomalies.

A comprehensive study of oceanic variability in the equatorial Pacific is presented in Kessler et al. (1996). Kelvin waves are excited very effectively by the Madden-Julian oscillation because they travel eastward with a similar speed. Also Rossby waves are excited by individual westerly wind bursts (Van Oldenborgh 2000). Inertia-gravity waves, which have periods of up to approximately one week (Philander 1990), play a role as well. A striking feature of oceanic variability is tropical instability waves associated with the high shear of the equatorial currents at the northern boundary of the cold tongue (Legeckis 1977). However, there is no evidence that these westward propagating structures are very relevant for El Niño variability. 
The spectra of the NINO3 index and the SOI in Figure $3 b$ are moderately peaked compared to those of many ICMs. Hence, it is generally agreed that noise contributes substantially to the irregularity and predictability of El Niño. This is confirmed by many studies of the effect of explicit stochastic forcing in ICMs and HCMs (e.g., Kleeman \& Power 1994, Blanke et al. 1997, Eckert \& Latif 1997). Roulston \& Neelin (2000) stressed a sometimes overlooked basic fact: For linear systems, it is not the high-frequency part of the spectrum of the noise that affects the slow timescale variability, but rather the low-frequency part. Case studies by McPhaden (1999) and Takayabu et al. (1999) of the development of the 1997/1998 El Niño and those by Vecchi \& Harrison (2000) of events in the period 1986-1998 point to a large role for variability associated with the Madden-Julian oscillation.

A more theoretical approach to study how a perturbation $\mathbf{x}\left(t_{0}\right)$, given at an initial time $t_{0}$, develops at later times $t$ is to linearize the system around a reference trajectory $\mathbf{x}_{r e f}(t)$, which gives the tangent model for $\mathbf{x}(t)$, i.e., $\mathbf{x}(t)=\mathrm{A}\left(t, t_{0}\right) \mathbf{x}\left(t_{0}\right)$, where $A=A\left[\mathbf{x}_{r e f}(t)\right]$. The adjoint $A^{T}$ of the tangent model can be used to study the sensitivity of a function of the final state to perturbations at earlier times (Oldenborgh et al. 1999). The singular vectors of A are the perturbation patterns that produce the largest effects on the final state. Mathematically, owing to the nonnormality of $A$, transient error growth can be larger than that of the fastest growing mode (Blumenthal 1991). Physically, this is related to the fact that disturbances propagate; perturbing the wind stress along the equator in the western Pacific has the largest effect on the NINO3 index a few months later. Transient error growth in a linearized version of the Cane-Zebiak model in a variety of parameter regimes was studied by Thompson \& Battisti (2000). Moore \& Kleeman (1999) extended the singular vector approach of a stable system by considering the collective effect of noise at all earlier times. The stochastic optimals, noise patterns that give the largest contribution to interannual variability, have a large overlap with westerly wind burst variability. Van Oldenborgh (2000) used the adjoint of an OGCM for studying what caused the development of the 1997/1998 El Niño. The initial-state wind anomaly of December 1996 and westerly wind bursts between December 1996 and May 1997 gave about equal contributions to the value of the NINO3 index in June 1997.

For large enough coupling, the mean state in ICMs is unstable, and the amplitude of the El Niño variability is set by nonlinear effects. However, even if the system is linearly stable, the system still exhibits oscillations when noise is present. In that case, the amplitude of the El Niño variability is determined by the noise characteristics. Nonlinearity can show up in a broadening or even splitting of the central part of the probability density function of an index. However, this does not happen in the observed NINO3 index time series, although it is significantly skewed (Burger \& Stephenson 1999). Originally, most research concentrated on the unstable regime, although the scenario of a stable oscillator excited by noise was already mentioned in the context of a HCM (Neelin 1990).

Analyzing sea-surface temperature observations, Penland \& Sardeshmukh (1995) concluded that El Niño variability is noise driven and can be explained 
by the constructive interferences of three damped modes. Chang et al. (1996) added stochastic forcing to an ICM and to an HCM and compared the behavior to a CGCM. Their results indicate that El Niño in the CGCM is likely to be noise driven. Moore \& Kleeman (1999) analyzed the sensitivity of an intermediate model to stochastic perturbations and suggested that El Niño is a stochastically forced phenomenon, with westerly wind bursts being an important ingredient of the noise.

Burgers (1999) investigated how well a single "stochastic oscillator" can describe El Niño. The assumption of a complex damped mode leads to the autocorrelation function $\rho(t)=\exp (-\kappa t) \cos (\omega t+\alpha) / \cos \alpha$, which is very much like observed results. A fit of the stochastic oscillator to observations of the NINO3 index yields $2 \pi / \omega=46 \pm 6$ months, $1 / \kappa=17 \pm 5$ months, and $\alpha=10^{\circ} \pm 5^{\circ}$. The fact that the spectra of the SOI and of the zonal-wind fluctuations show a white background and that the NINO3 index hardly shows any fits nicely with a picture of El Niño as stochastic oscillator driven by atmospheric noise. However, part of this white background could be due to observational noise, and the periods of rapid rise and decline of the 1997/1998 El Niño do not fit into a simple stochastic-oscillator picture.

The picture that emerges from these studies is that of noise as the major limiting factor for the predictability of El Niño, at least for the first few seasons ahead. The record of El Niño indices is too short to determine directly whether the El Niño system is stable or not, although it is clear that the stability properties depend on the season. Probably, the system is close to neutral, with noise having a significant influence on the El Niño variability.

\subsection{External Processes and Decadal Variability}

When one considers the spectrum of the NINO3 index, energy is found also in lower frequencies, in particular in the decadal/interdecadal range. Perhaps the longest record analyzed is that compiled by Quinn et al. (1987) of El Niño occurrences since 1525. The strength of El Niño before the mid-1970s seems to be smaller than that after this period. According to NCEP data, the standard deviations of the SOI (NINO3) for 1951-1975 is 1.64 (0.81), compared to 1.84 (1.00) for 19762000. The spatial patterns of this decadal change are fairly similar to that of the interannual variability, but the sea-surface temperature anomalies at the eastern side of the basin have a broader meridional extent.

What is the origin of this (inter)decadal variability? A possible mechanism is that white noise leads to decadal variability (Kirtman \& Schopf 1998). Latif et al. (1998) have studied decadal variations induced by stochastic forcing in an HCM. Flügel \& Chang (1996) provided modeling evidence for stochastically induced shifts in El Niño behavior. For the stochastic oscillator (Burgers 1999), this leads, for instance, to variations of approximately $20 \%$ in the standard deviation of 15-year segments, or $10 \%$ in 45-year segments. These variations are of the same order of magnitude as those observed. A second possible mechanism is that of complex nonlinear interactions between the basin-scale instabilities and 
smaller-scale processes. After all, the deterministic system may be chaotic and contain a component of low-frequency variability. Finally, the mean state on which the El Niño mode oscillates may be changed by external processes on a decadal timescale.

With respect to the latter possibility, it is recognized that the equatorial Pacific is part of the global climate system. The equatorial atmospheric circulation in the Pacific is intrinsically linked to extratropical circulation systems and the Asian monsoon system. The equatorial-surface ocean-current system connects to the midlatitude circulation in the North and South Pacific. Through transport of heat, both the thermocline shape and the subsurface temperature may be changed on timescales that are controlled by processes other than those involved in El Niño.

In some simulations using global climate models, the dominant mechanism of low-frequency variability of El Niño has its origin in the decadal variability in the extratropical atmospheric winds (Barnett et al. 1999, Pierce et al. 2000). The large-scale changes influence the trade winds and precondition the mean state of the thermocline in the equatorial ocean leading to prolonged periods of enhanced or reduced El Niño variability. Wang \& Weisberg (1998) stressed the importance of the coupling between Walker and Hadley circulation to produce out-of-phase differences between tropical and extratropical sea-surface temperature anomalies.

There is also a clear linking of the Walker circulation with the Atlantic and the South Asian monsoon (Webster et al. 1996). Each year in northern spring, the center of tropical convection migrates from the western Pacific warm pool to the northwest, announcing the arrival of the Asian monsoon. The normal low-pressure system over the western Pacific shifts eastwards during El Niño events. Because of anomalous high pressure over the western Pacific/South Asian continent, precipitation is decreased, and generally, a weak Asian summer monsoon results. On the other hand, a strong monsoon with heavy rains and corresponding strong easterly winds tends to oppose El Niño conditions. This relation has weakened over the last decades, and no abnormal precipitation has been found with increased El Niño occurrences (Kumar et al. 1999).

Subsurface propagation of midlatitude ocean-temperature anomalies may also lead to interdecadal variability ( $\mathrm{Gu} \&$ Philander 1997). Temperature anomalies are formed in the winter mixed layer at midlatitudes, subduct when restratification occurs, propagate along the subtropical gyre, and affect the tropical thermocline. Changes in tropical sea-surface temperature influence the midlatitude wind patterns, which in turn affect the temperature in the midlatitude mixed layer, providing for an oscillation with an (inter)decadal timescale. In Zhang et al. (1998), observational evidence is presented of subsurface temperature anomalies, which propagate over a period of approximately 10 years from the North Pacific to the low-latitude Pacific. However, recent studies have indicated that these anomalies may not reach the equatorial region with sufficient amplitude to affect El Niño dynamics (Hazeleger et al. 2001). Other oceanic connections have been suggested, such as $(a)$ the signal of extratropical waves into the western equatorial Pacific (Lysne et al. 1997) and (b) the coupling of the meridional extent of the cold tongue 
to the shallow meridional overturning circulation connecting the equatorial upwelling region and the North Pacific subtropical gyre (Kleeman et al. 1999).

\section{DISCUSSION}

Apart from trying to understand the basic physics of El Niño variability, most of the studies cited here were carried out $(a)$ to predict the occurrence of the next El Niño events and/or $(b)$ to determine the changes of El Niño variability due to increased levels of greenhouse gases in the atmosphere.

The first issue is intimately related to how well one is able to model the link between the interannual basin-wide fluctuations associated with El Niño and the shorter time-and smaller space-scale variability in the Pacific. Different types of models are used to provide El Niño forecasts, ranging from statistical schemes to high-resolution coupled CCGMs. These can incorporate information from different data sources, e.g., in combining subsurface data with wind-stress data and seasurface temperature data. CGCMs can readily calculate the response to global seasurface temperature patterns, which is important for finding the teleconnections between equatorial variability and effects elsewhere in the world. However, the best statistical schemes are still competitive with the best CGCMs. One of the reasons is probably that El Niño is dominated by a single oscillatory mode, causing any system that can have sine-like solutions to have success, at least initially. To improve on this initial success, it is hard to find the right balance of the coupled processes because the way the various feedbacks and noise sources interact is quite subtle. None of the models predicted well the onset of the 1997-1998 El Niño, but once this event was well underway, predictions of subsequent development were reasonable. Interpreting the past and future observations with the concepts from ICMs will make it possible to evaluate much more systematically the performance of CGCMs and allow them to be improved substantially.

The second issue is related to how well one is able to model the link between El Niño variability and the global climate system. Although immediate verification from available observations is possible for forecasting El Niño, this is hardly an option on the timescale on which the global climate is changing. To properly capture El Niño variability, global models should have enough resolution to represent (a) long-wave ocean adjustment, (b) the basic coupled feedbacks, (c) a representation of diabatic processes that provides the correct atmosphere response to equatorial sea-surface temperature anomalies (Newman et al. 2000), and $(d)$ the influence of the annual mean state on El Niño variability.

The qualitative different results so far clearly show that modeling the effect of global warming on El Niño variability is still in its infancy. In some models (Knutson et al. 1997), the mean zonal sea-surface temperature gradient decreases, with little change in El Niño-like activity. In others models (Timmermann et al. 1999), increasing greenhouse-gas concentrations induce a more El Niño-like mean state with more pronounced cold events than warm events. In the second Hadley 
Centre model (Collins 2000a), changes in El Niño activity, frequency, and phase locking are found. However, in the third Hadley Centre model, no change in El Niño statistics is found (Collins 2000b). This is attributed to the differences in physical parameterization and not to the differences in resolution between the two versions. In one coupled model (Noda et al. 1999), a change toward a more La Niña-like mean state is found.

The latter problems indicate that still much work has to be done in the coming decades to get better solutions to these problems. Considering that the connection between oceanic and atmospheric phenomena was only discovered in 1969 (Bjerknes 1969), the subject has undergone a rapid transition to maturity. At the moment, the spatio/temporal patterns of interannual El Niño variability are well characterized, their dynamics is reasonably well understood, and a diversity of models is used to predict the state of the Pacific a few months in advance. This work is continually stimulated by El Niño, which uncovers itself patiently every few years to have us learn a bit more of its identity.

\section{ACKNOWLEDGMENTS}

Work on this review was supported by the Netherlands Organization for Scientific Research (NWO) under a NWO-PIONIER grant to H.A.D. The authors thank Geert Jan van Oldenborgh (KNMI) for many discussions and for making the Climate Explorer tool, Gerbrand Komen (KNMI) for comments on the manuscript, Mojib Latif (MPI, Hamburg) for sending us a preprint of the ENSIP study, and David Neelin (UCLA, Los Angeles) and Paul van der Vaart (IMAU, Utrecht) for collaboration over the years.

\section{Visit the Annual Reviews home page at www.AnnualReviews.org}

\section{LITERATURE CITED}

Anderson D, McCreary J. 1985. Slowly propagating disturbances in a coupled oceanatmosphere model. J. Atmos. Sci. 42:615-29

Barnett TP, Pierce DW, Latif M, Dommenget D, Saravanan R. 1999. Interdecadal interactions between the tropics and midlatitudes in the Pacific basin. Geophys. Res. Lett. 26:61518

Battisti D, Hirst AC. 1989. Interannual variability in a tropical atmosphere-ocean model: influence of the basic state, ocean geometry and nonlinearity. J. Atmos. Sci. 46:1687-712

Bjerknes J. 1969. Atmospheric teleconnections from the equatorial Pacific. Mon. Weather Rev. 97:163-72
Blanke B, Neelin JD, Gutzler D. 1997. Estimating the effect of stochastic wind stress forcing on ENSO irregularity. J. Clim. 10:147386

Blumenthal M. 1991. Predictability of a coupled ocean-atmosphere model. J. Clim. 4:766-84

Boulanger J-P, Menkes C. 1999. Long equatorial wave reflection in the Pacific Ocean from TOPEX/Poseidon data during the 19921998 period. Clim. Dyn. 15:205-25

Burgers G. 1999. The El Niño stochastic oscillator. Clim. Dyn. 15:352-75

Burgers G, Stephenson D. 1999. The normality of El Niño. Geophys. Res. Lett. 26:1027-30 
Cane MA, Moore DW. 1981. A note on lowfrequency equatorial basin modes. J. Phys. Oceanogr. 11:1578-84

Cane MA, Sarachik ES. 1977. Forced baroclinic ocean motions. II. The linear equatorial bounded case. J. Mar. Res. 35:395-432

Chang P, Ji L, Ji H, Flügel M. 1996. Chaotic dynamics versus stochastic processes in El Niño-Southern Oscillation in a coupled ocean-atmosphere model. Physica D98:30120

Chang P, Wang B, Li T, Ji L. 1994. Interactions between the seasonal cycle and the Southern Oscillation-frequency entrainment and chaos in a coupled ocean-atmosphere model. Geophys. Res. Lett. 21:2817-20

Cheney R, Miller L, Agreen R, Doyle N, Lillibridge L. 1994. TOPEX/POSEIDON: the 2 cm solution. J. Geophys. Res. 99:24555-64

Collins M. 2000a. The El Niño-Southern Oscillation in the second Hadley Centre Coupled model and its response to greenhouse warming. J. Clim. 13:1299-312

Collins M. 2000b. Understanding uncertainties in the response of ENSO to greenhouse warming. Geophys. Res. Lett. 27:3509-12

Delecluse P, Davey M, Kitamura Y, Philander SGH, Suarez M, Bengtsson L. 1998. Coupled general circulation modeling of the tropical Pacific. J. Geophys. Res. 103:1435774

Dijkstra HA. 2000. Nonlinear Physical Oceanography. Dordrecht, The Netherlands: Kluwer. 456 pp.

Dijkstra HA, Neelin JD. 1995. Coupled oceanatmosphere models and the tropical climatology. II. Why the cold tongue is in the east. $J$. Clim. 8:1343-59

Eckert C, Latif M. 1997. Predictability of a stochastically forced hybrid coupled model of the Tropical Pacific ocean-atmosphere system. J. Clim. 10:1488-504

Flügel M, Chang P. 1996. Stochastically induced climate shift of El Niño-Southern Oscillation. Geophys. Res. Lett. 26:2473-76

Gill AE. 1980. Some simple solutions for heat induced tropical circulation. Q. J. R. Meteorol. Soc. 106:447-62
Glantz M. 2000. Currents of Change. Cambridge, UK: Cambridge Univ. Press. 2nd ed. Goddard L, Philander SGH. 2000. The energetics of El Niño and La Niña. J. Clim. 13:1496516

Gu D, Philander SGH. 1997. Interdecadal climate fluctuations that depend on exchanges between the tropics and extratropics. Science 275:805-7

Hazeleger W, Visbeck M, Cane MA, Karspeck A, Naik N. 2001. Decadal upper ocean temperature variability in the Tropical Pacific. $J$. Geophys. Res. 106:8971-88

Hirst AC. 1986. Unstable and damped equatorial modes in simple coupled oceanatmosphere models. J. Atmos. Sci. 43:60630

Jin FF. 1997a. An equatorial recharge paradigm for ENSO. I. Conceptual model. J. Atmos. Sci. 54:811-29

Jin FF. 1997b. An equatorial recharge paradigm for ENSO. II. A stripped-down coupled model. J. Atmos. Sci. 54:830-47

Jin FF, An S-I. 1999. Thermocline and zonal advective feedbacks within the equatorial ocean recharge oscillator model for ENSO. Geophys. Res. Lett. 26:2989-92

Jin FF, Neelin JD. 1993. Modes of interannual tropical ocean-atmosphere interaction-a unified view. I. Numerical results. J. Atmos. Sci. 50:3477-503

Jin FF, Neelin JD, Ghil M. 1994. El Niño on the devil's staircase: annual subharmonic steps to chaos. Science 264:70-72

Jin FF, Neelin JD, Ghil M. 1996. El Niño/ Southern Oscillation and the annual cycle: subharmonic frequency locking and aperiodicity. Physica D 98:442-65

Kaplan A, Cane MA, Kushnir Y, Clement AC, Blumenthal MB, Rajagopalan B. 1998. Analyses of global sea surface temperature 1856-1991. J. Geophys. Res. 103:1856789

Kessler W, Spillane M, McPhaden M, Harrison D. 1996. Scales of variability in the equatorial Pacific inferred from the tropical atmosphere-ocean array. J. Clim. 9:29993024 
Kirtman B, Schopf P. 1998. Decadal variability in ENSO predictability and prediction. $J$. Clim. 11:2804-22

Kleeman R. 1991. A simple model of the atmospheric response to ENSO sea surface temperature anomalies. J. Atmos. Sci. 48:3-18

Kleeman R, Power S. 1994. Limits to the predictability in a coupled ocean-atmosphere model. Tellus 46A:529-40

Kleeman RP, McCreary JP, Klinger B. 1999. A mechanism for generating ENSO decadal variability. Geophys. Res. Lett. 26:1743-46

Knutson T, Manabe S, Gu D. 1997. Simulated ENSO in a global coupled ocean-atmosphere model: multidecadal amplitude modulation and $\mathrm{CO}_{2}$ sensitivity. J. Clim. 10:42-63

Können G, Jones P, Kaltofen M, Allan R. 1998. Pre-1866 extensions of the Southern Oscillation index using early Indonesian and Tahitian meteorological readings. J. Clim. 11:2325-39

Kumar KK, Rajagopalan B, Cane MA. 1999. On the weakening relationship between the Indian monsoon and ENSO. Science 284:2156-59

Latif M, Anderson D, Barnett TP, Cane M, Kleeman R, et al. 1998. A review of the predictability and prediction of ENSO. J. Geophys. Res. 103:14375-93

Legeckis R. 1977. Long waves in the eastern equatorial Pacific Ocean. Science 197:117981

Lysne J, Chang P, Giese B. 1997. Impact of extratropical Pacific on equatorial variability. Geophys. Res. Lett. 24:2589-92

Madden R, Julian P. 1994. Observations of the 40-50-day tropical oscillation-a review. Mon. Weather Rev. 122:814-35

Mantua NJ, Battisti DS. 1995. Aperiodic variability in the Zebiak-Cane coupled oceanatmosphere model: air-sea interaction in the western equatorial Pacific. J. Clim. 8:2897927

McPhaden M. 1999. Genesis and evolution of the 1997-1998 El Niño. Science 283:950-54

McPhaden MJ. 1998. The tropical ocean-global atmosphere observing system: a decade of progress. J. Geophys. Res. 103:14169-240
McPhaden MJ, Yu X. 1999. Equatorial waves and the 1997-1998 El Niño. Geophys. Res. Lett. 26:2961-64

Moore AM, Kleeman R. 1999. Stochastic forcing of ENSO by the intraseasonal oscillation. J. Clim. 12:1199-220

Moore DW. 1968. Planetary-Gravity Waves in an Equatorial Ocean. Cambridge, MA: Harvard Univ. Press

Münnich MM, Cane M, Zebiak SE. 1991. A study of self-excited oscillations of the tropical ocean-atmosphere system. II. Nonlinear cases. J. Atmos. Sci. 48:1238-48

Neelin JD. 1990. A hybrid coupled general circulation model for El Niño studies. J. Atmos. Sci. 47:647-93

Neelin JD. 1991. The slow sea surface temperature mode and the fast-wave limit: analytic theory for tropical interannual oscillations and experiments in a hybrid coupled model. J. Atmos. Sci. 48:584-606

Neelin JD, Battisti DS, Hirst AC, Jin F-F, Wakata Y, et al. 1998. ENSO theory. J. Geophys. Res. 103:14261-90

Neelin JD, Dijkstra HA. 1995. Coupled oceanatmosphere models and the tropical climatology. I. The dangers of flux correction. $J$. Clim. 8:1325-42

Neelin JD, Jin F-F. 1993. Modes of interannual tropical ocean-atmosphere interaction-a unified view. II. Analytical results in the weak-coupling limit. J. Atmos. Sci. 50:350422

Neelin JD, Latif M, Jin F-F. 1994. Dynamics of coupled ocean-atmosphere models: the tropical problem. Annu. Rev. Fluid Mech. 26:61759

Neelin JD, Zeng N. 2000. The first quasiequilibrium tropical circulation model-formulation. J. Atmos. Sci. 57:1741-66

Newman M, Sardeshmukh P, Bergman J. 2000. An assesment of the NCEP, NASA and ECMWF reanalyses over the tropical west Pacific warm pool. Bull. Am. Meterol. Soc. 81:41-48

Noda A, Yoshimatsu K, Yukimoto S, Yamaguchi K, Yamaki S. 1999. Relationship between natural variability and $\mathrm{CO}_{2}$-induced 
warming pattern: MRI AOGCM experiment. In Proc. 10th Symp. Global Change Studies, 10-15 Jan., 1999, Dallas, Texas, 24:359-62. Boston, MA: Am. Meteorol. Soc.

Penland C, Sardeshmukh PD. 1995. The optimal growth of tropical sea surface temperature anomalies. J. Clim. 8:1999-2024

Philander SGH. 1990. El Niño and the Southern Oscillation. New York: Academic. 291 pp.

Philander SGH, Gu D, Halpern D, Lambert G, Lau N-C, et al. 1996. Why the ITCZ is mostly north of the equator. J. Clim. 9:295872

Philander SGH, Yamagata T, Pacanowski RC. 1984. Unstable air-sea interactions in the tropics. J. Atmos. Sci. 41:604-13

Picaut J, Masia I, du Penhoat Y. 1996. An advective-reflective conceptual model for the oscillatory nature of ENSO. Science 277: 663-66

Pierce DW, Barnett TP, Latif M. 2000. Connections between the Pacific Ocean tropics and midlatitudes on decadal timescales. J. Clim. 13:1173-94

Quinn WH, Neal VT, Antunez de Mayolo S. 1987. El Niño occurrences over the past four and a half centuries. J. Geophys. Res. 92:14449-61

Reynolds R, Smith T. 1994. Improved global sea surface temperature analyses using optimum interpolation. J. Clim. 7:929-48

Roulston M, Neelin J. 2000. The response of an ENSO model to climate noise, weather noise and intraseasonal forcing. Geophys. Res. Lett. 27:3723-26

Schneider E, Huang B, Shukla J. 1995. Ocean wave dynamics and El Niño. J. Clim. 45:2415-39

Schopf PS, Suarez M. 1990. Ocean wave dynamics and the timescale of ENSO. J. Phys. Oceanogr. 20:629-45

Slingo J, Rowell D, Nortley KSF. 1999. On the predictability of the interannual behaviour of the Madden-Julian oscillation and its relationship with El Niño. Q. J. R. Meterol. Soc. 125:583-609

Stricherz J, Legler D, O'Brien J. 1997. TOGA Pseudo-Stress Atlas 1985-1994, Volume II:
Pacific Ocean. Tallahassee, FL: Florida State Univ. Press. 158 pp.

Suarez M, Schopf PS. 1988. A delayed action oscillator for ENSO. J. Atmos. Sci. 45:328387

Takayabu Y, Iguchi T, Kachi M, Shibata A, Kanzawa H. 1999. Abrupt termination of the 1997-1998 El Niño in response to a MaddenJulian oscillation. Nature 402:279-82

Thompson C, Battisti D. 2000. A linear stochastic dynamical model of ENSO. Part I. Model development. J. Clim. 13:2818-32

Timmermann A, Oberhuber J, Esch M, Latif M, Roeckner E. 1999. Increased El Niño frequency in a climate model forced by future greenhouse warming. Nature 398:69497

Tziperman E, Cane MA, Zebiak SE. 1995. Irregularity and locking to the seasonal cycle in an ENSO prediction model as explained by the quasi-periodicity route to chaos. J. Atmos. Sci. 52:293-306

Tziperman E, Cane MA, Zebiak SE, Xue Y, Blumenthal B. 1998. Locking of El Niño's peak time to the end of the calendar year in the delayed oscillator picture of ENSO. $J$. Clim. 11:2191-99

Tziperman E, Stone L, Cane MA, Jarosh H. 1994. El Niño chaos: overlapping of resonances between the seasonal cycle and the Pacific ocean-atmosphere oscillator. Science 264:72-74

Tziperman E, Zebiak SE, Cane MA. 1997. Mechanisms of seasonal-ENSO interaction. J. Atmos. Sci. 54:61-71

Van der Vaart PCF, Dijkstra HA, Jin F-F. 2000. The Pacific Cold Tongue and the ENSO mode: unified theory within the Zebiak-Cane model. J. Atmos. Sci. 57:967-88

Van Oldenborgh GJ. 2000. What caused the onset of the 1997/98 El Niño? Mon. Weather Rev. 128:2601-7

Van Oldenborgh GJ, Burgers G, Venzke S, Eckert C, Giering R. 1999. Tracking down the ENSO-delayed oscillator with an adjoint OGCM. Mon. Weather Rev. 127:1477-95

Vecchi GA, Harrison DE. 2000. Tropical Pacific sea surface temperature anomalies, 
El Niño, and equatorial westerly wind events. J. Clim. 13:1814-30

Walker GT. 1924. Correlation in seasonal variations of weather. IX. A further study of world weather. Mem. India Meteorol. Dep. 24:275332

Wang C, Weisberg RH. 1998. Climate variability of the coupled tropical-extra-tropical ocean-atmosphere system. Geophys. Res. Lett. 25:3879-982

Wang C, Weisberg RH, Virmani JI. 1999. Western Pacific interannual variability associated with the El Niño-Southern Oscillation. J. Geophys. Res. 104:5131-49

Webster P. 1996. Monsoons: processes, predictability, and the prospects for predicting. J. Geophys. Res. 103:14451-510

Weller R, Anderson S. 1996. Surface meteorology and air-sea fluxes in the western equatorial Pacific warm pool during the TOGA-Coupled Ocean-Atmosphere Response experiment. J. Clim. 9:1959-90
Wyrtki K. 1981. An estimate of equatorial upwelling in the Pacific. J. Phys. Oceanogr. 11:1205-14

Xie P, Arkin P. 1997. Global precipitation: a 17year monthly analysis based on gauge observations, satellite measurements and numerical model outputs. Bull. Am. Meterol. Soc. 78:2539-58

Xie SP, Philander SGH. 1994. A coupled ocean-atmosphere model of relevance to the ITCZ in the eastern Pacific. Tellus 46A:34050

Zebiak SE. 1982. A simple atmospheric model of relevance to El Niño. J. Atmos. Sci. 39:2017-27

Zebiak SE, Cane MA. 1987. A model El Niño-Southern Oscillation. Mon. Weather Rev. 115:2262-78

Zhang R-H, Rothstein LM, Busalacchi A. 1998. Origin of upper-ocean warming and El Niño change on decadal scales in the tropical Pacific Ocean. Science 391:879-82 

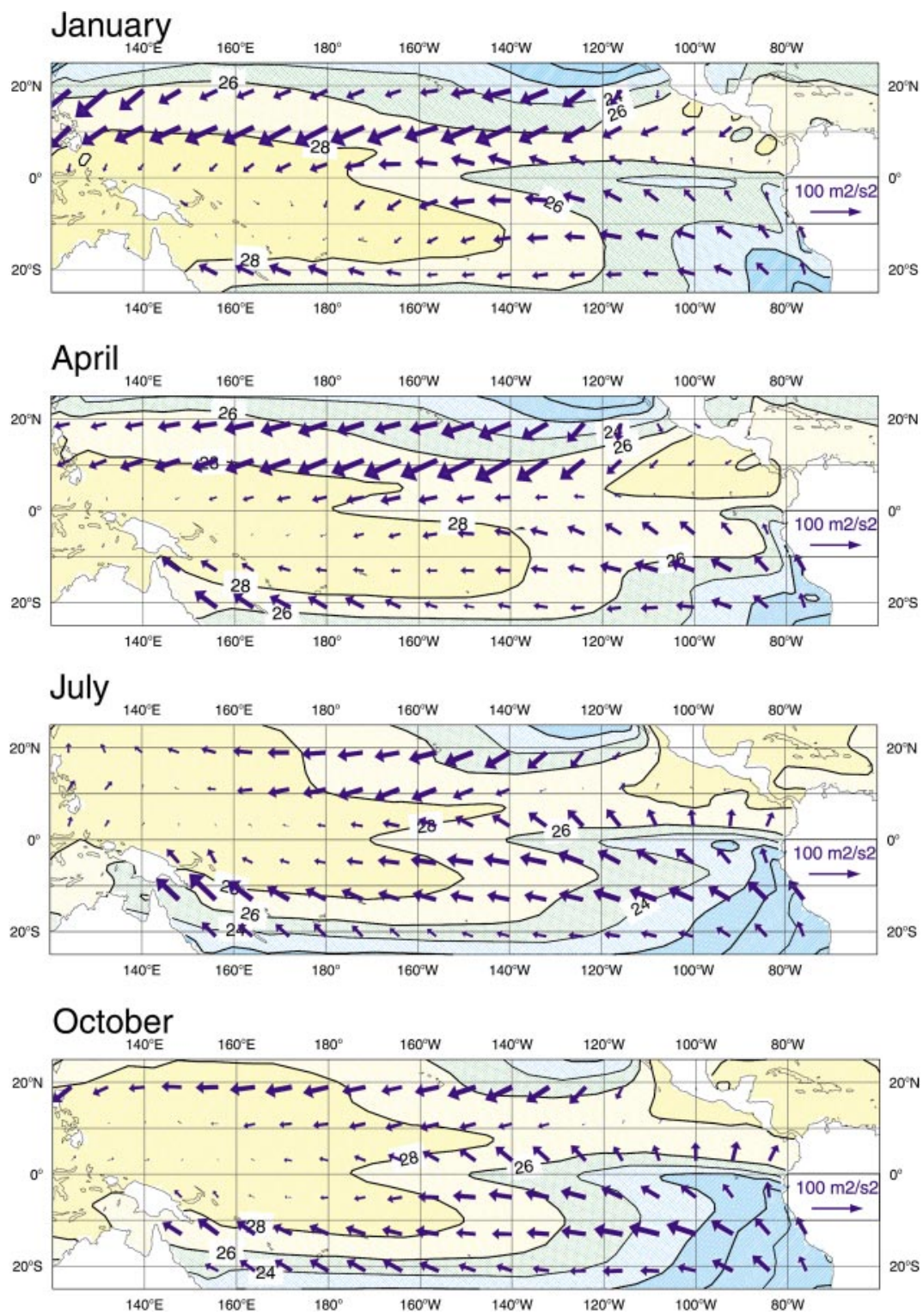

Figure 1 Sea-surface temperature and windstress climatologies for January, April, July, and October. The contours give the 1961-1990 sea-surface temperature climatology (contour interval $2^{\circ} \mathrm{C}$ ) from NCEP (National Center for Environmental Prediction) (Smith et al. 1996). Arrows represent the 1961-1992 pseudowindstress climatology (in $\mathrm{m}^{2} \mathrm{~s}^{-2}$ ) from FSU (Florida State University) (Stricherz et al. 1997). Pseudowindstress has the direction of the surface wind and the magnitude of the wind speed squared. 

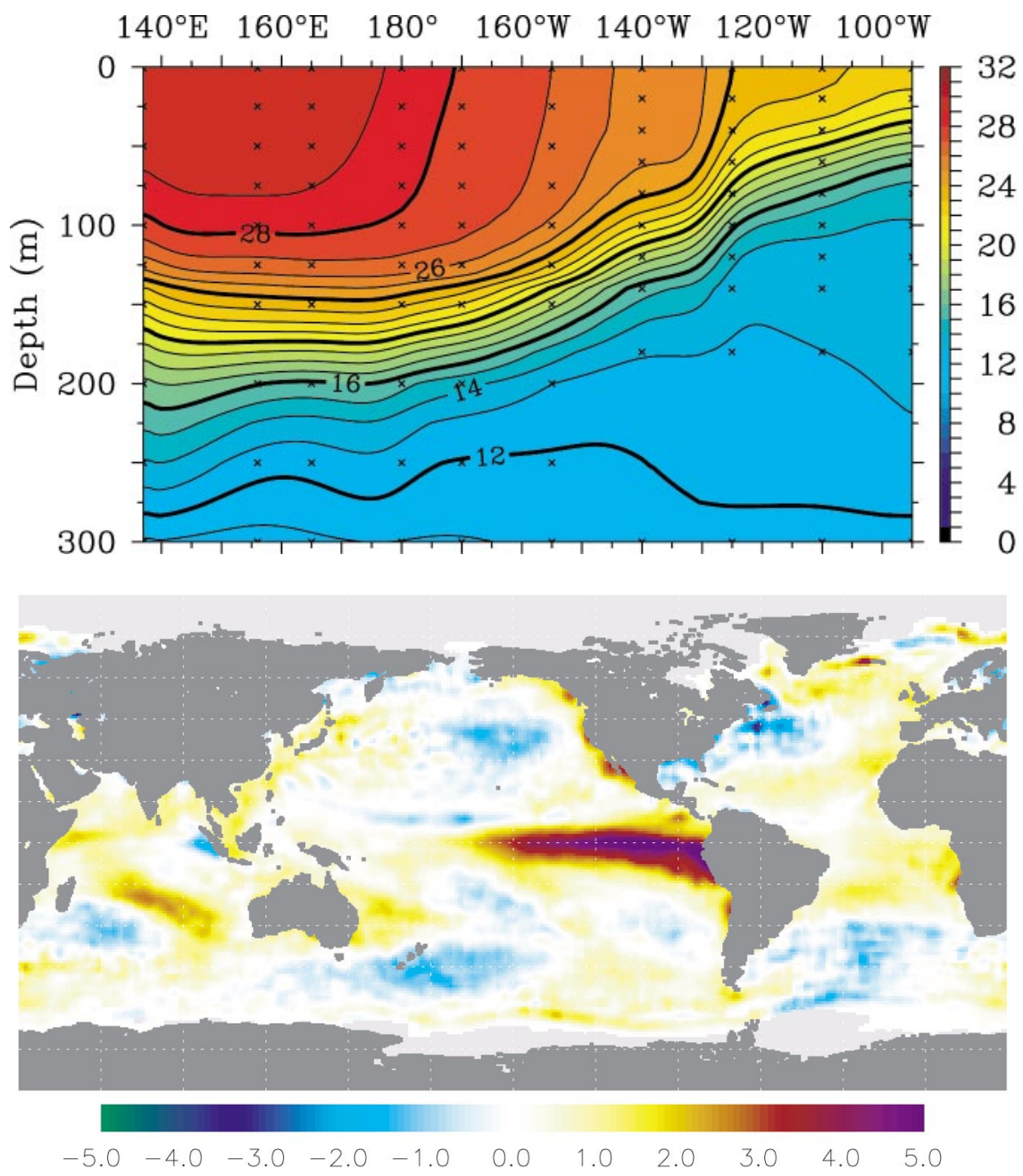

Figure 2 (top) Temperature $\left({ }^{\circ} \mathrm{C}\right.$ ) in September 2000 along the equator as a function of depth and longitude, measured by the TAO/TRITON array, showing the thermocline. Plot made with data and software from http://www.pmel.noaa.gov/tao. (bottom) Seasurface temperature anomaly field of December 1997, at the height of the 1997/1998 El Niño. Data from NCEP. 
(a)

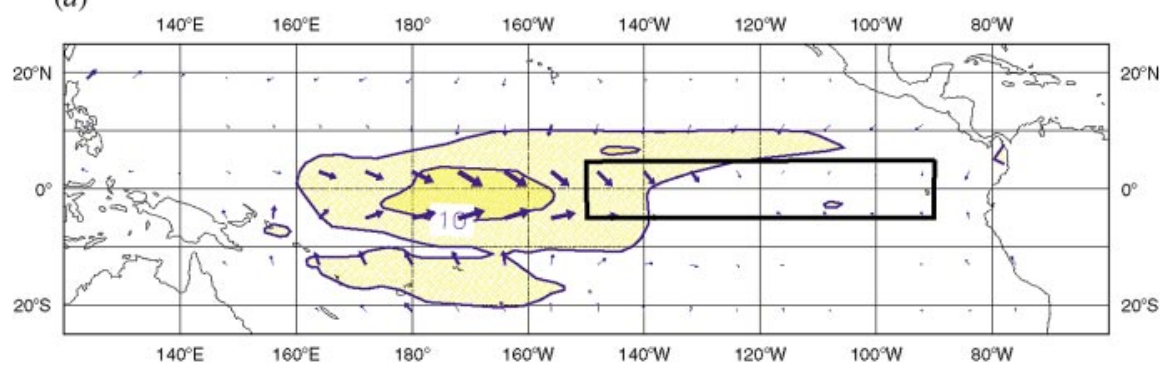

(b)

Zonal Find Anomalies (m $\left.\mathrm{s}^{-1}\right)$

SST Anomalies ( $\mathrm{C} C \mathrm{C})$

$200 \mathrm{C}$ sothern Depth Anomalies (m)

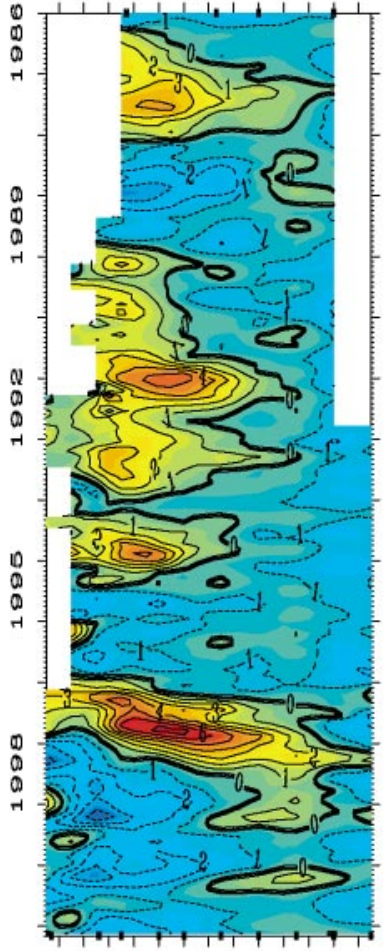

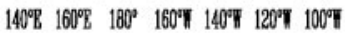

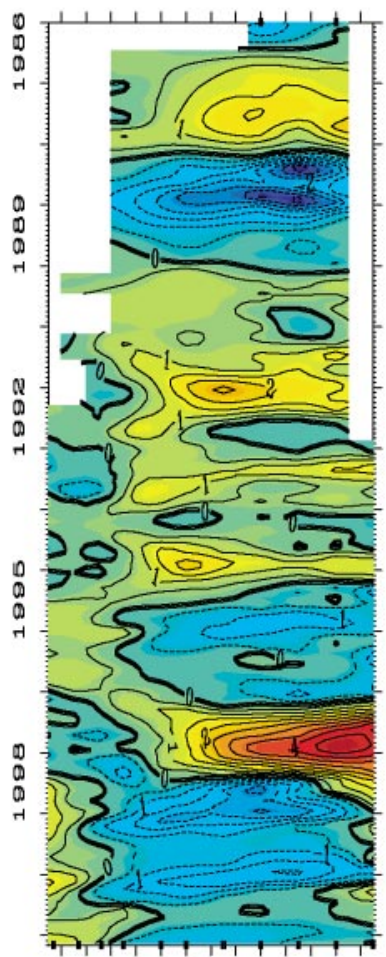

$1400^{\circ} \quad 1600^{\circ} \quad 180^{\circ} 160 \%$ T $140 \% 120 \%$ T $100 \%$

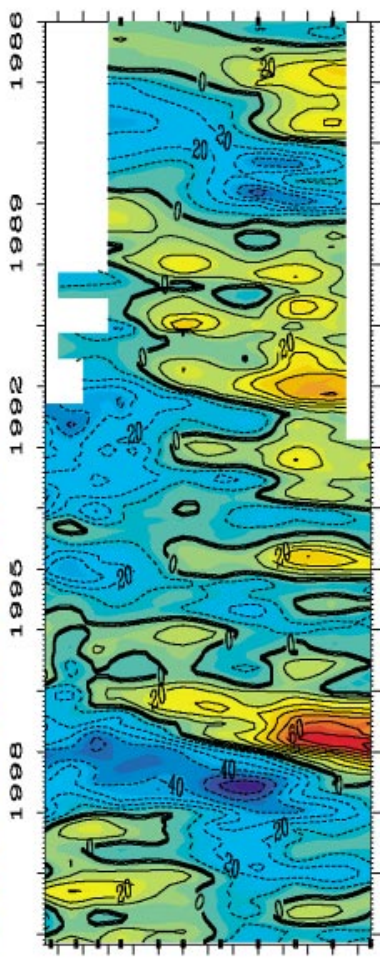

$140^{\circ} \mathrm{B} 160^{\circ} \mathrm{B} 180^{\circ} 1000 \% 140 \% 120 \% 100 \%$

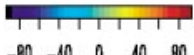

Figure 4 (a) Response of pseudowindstress to NINO3 anomalies, from a regression of observed FSU pseudowindstress fields to the NCEP NINO3 index over the period 1968-1999. The NINO3 area is indicated by the rectangular box. Pseudowindstress has the direction of the surface wind and the magnitude of the wind speed squared. Contours at the 5 and $10 \mathrm{~m}^{2}$ $\mathrm{s}^{-2} \mathrm{~K}^{-1}$ denote the magnitude of the response. $(b)$ Time-longitude diagrams of equatorial anomalies of zonal wind, sea-surface temperature and depth of the $20^{\circ}$ isotherm (a measure of the thermocline depth) for the period 1986-2000, as measured by the TAO/TRITON array. Plot made with data and software from http://www.pmel.noaa.gov/tao. 


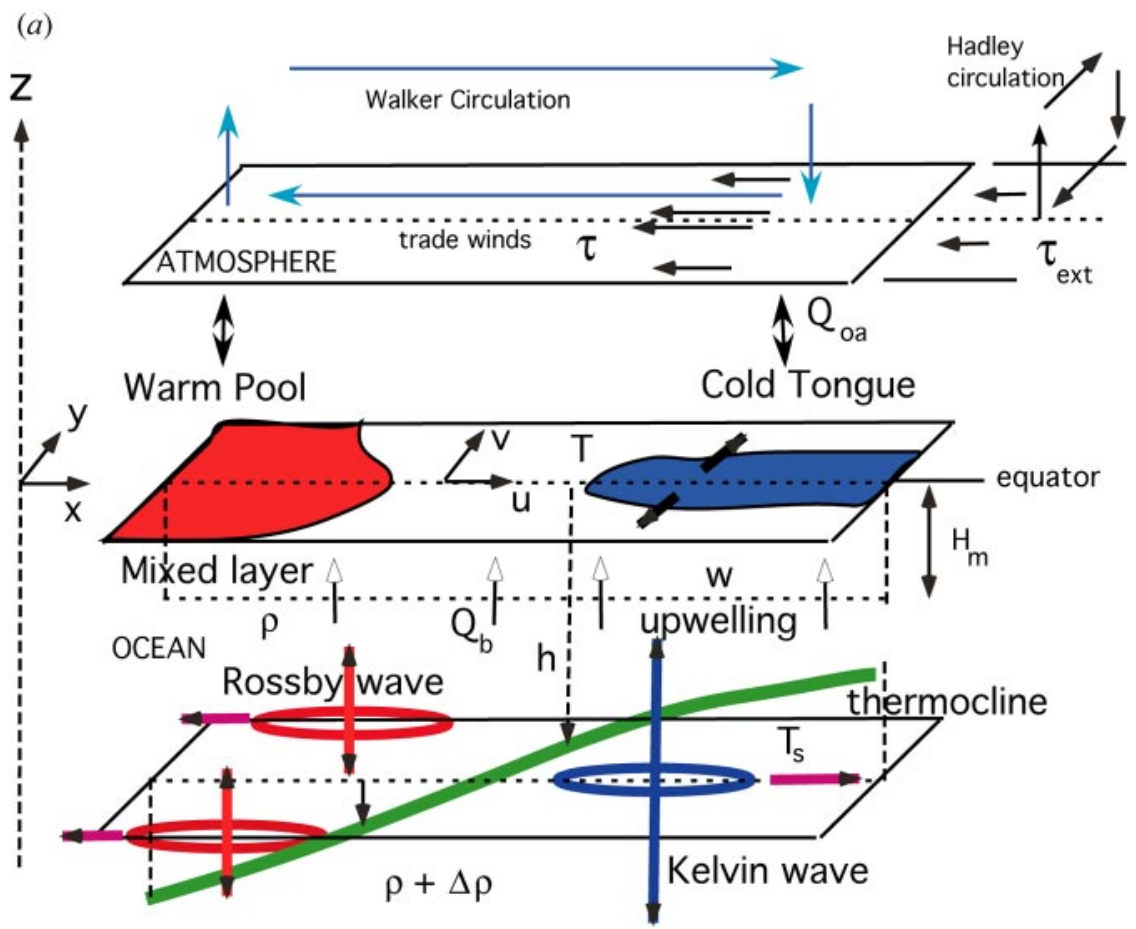

(b)

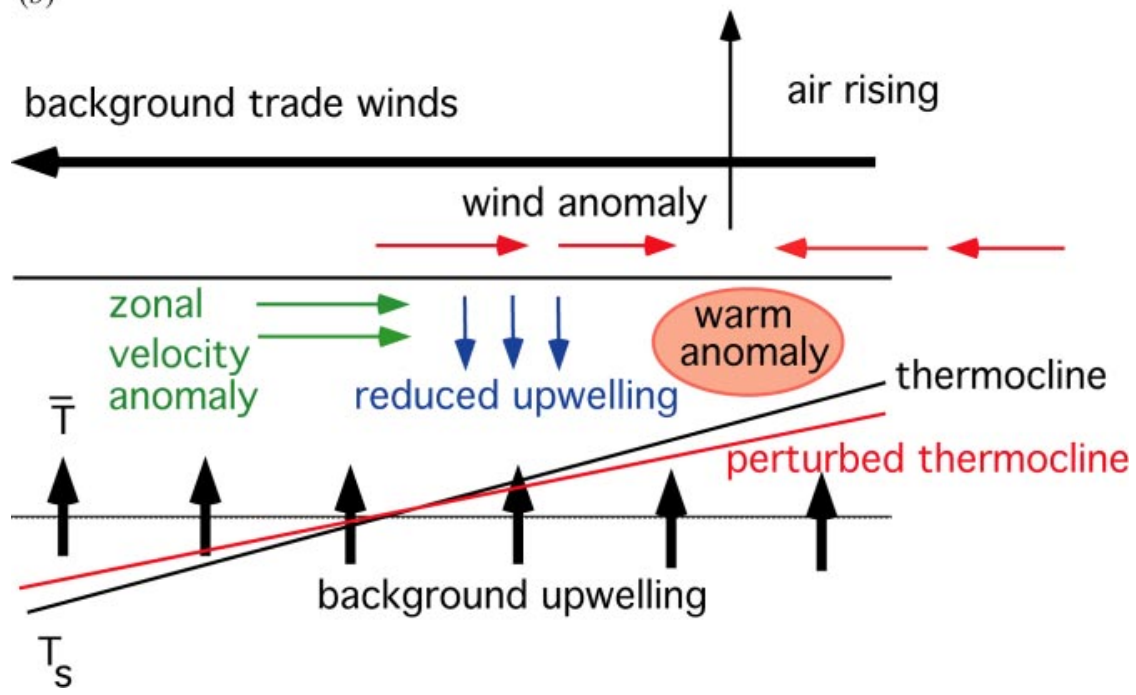

Figure 5 (a) Overview of the oceanic and atmospheric processes of the equatorial coupled ocean-atmosphere system. (b) Sketch to illustrate the thermocline feedback (red arrows), the upwelling feedback (blue arrows), and the zonal advection feedback (green arrows). 


\section{CONTENTS}

FRONTISPIECE

Milton VAN DyKe, THE MAN AND hIS WORK, Leonard W. Schwartz 1

G.K. BATCHELOR AND THE HOMOGENIZATION OF TURBULENCE, H.K. Moffatt

DAVID CRIGHTON, 1942-2000: A COMMENTARY ON HIS CAREER AND HIS INFLUENCE ON AEROACOUSTIC THEORY, John E. Ffowcs Williams 37

Sound Propagation Close to the Ground, Keith Attenborough 51

ELLIPTICAL INSTABILITY, Richard R. Kerswell 83

LAGRANGIAN INVESTIGATIONS OF TURBULENCE, P.K. Yeung 115

CAVITATION In VortiCAL Flows, Roger E.A. Arndt 143

Microstructural Evolution in POLYMER Blends, Charles $L$. Tucker III and Paula Moldenaers 177

Cellular Fluid Mechanics, Roger D. Kamm 211

DynAmiCAl PHENOMENA In LIQUID-CRYSTALline MATERIALS, Alejandro D. Rey and Morton M. Denn 233

Noncoalescence And Nonwetting Behavior of LiQuids, $G$. Paul Neitzel and Pasquale Dell' Aversana

BOUNDARY-LAYER RECEPTIVITY TO FREESTREAM DISTURBANCES, William S. Saric, Helen L. Reed, and Edward J. Kerschen

One-Point Closure Models For BuOyancy-Driven Turbulent FLOWS, K. Hanjalić

Wall-Layer Models for Large-EdDy Simulations, Ugo Piomelli and Elias Balaras

FILAMENT-STRETCHING RHEOMETRY OF COMPLEX FLUIDS, Gareth $H$. McKinley and Tamarapu Sridhar

Molecular Orientation EFFeCtS IN Viscoelasticity, Jason K.C. Suen, Yong Lak Joo, and Robert C. Armstrong

THE RICHTMYER-MESHKOV INSTABILITY, Martin Brouillette

SHIP WAKES AND THEIR RADAR IMAGES, Arthur M. Reed and Jerome H. Milgram 
SYNTHETIC JETS, Ari Glezer and Michael Amitay

FluID DYNAMICS OF El NiÑO VARIABILITY, Henk A. Dijkstra and

Gerrit Burgers

INTERNAL GRAVITY WAVES: FROM INSTABILITIES TO TURBULENCE,

C. Staquet and J. Sommeria

INDEXES

Subject Index

Cumulative Index of Contributing Authors, Volumes 1-34

Cumulative Index of Chapter Titles, Volumes 1-34

ERRATA

An online log of corrections to the Annual Review of Fluid Mechanics chapters may be found at http://fluid.annualreviews.org/errata.shtml 